\title{
A Case Study Investigating Whether the Process of Resolving Interpersonal Problems in Couple Therapy Is Isomorphic to the Process of Resolving Problems in Individual Therapy
}

\author{
HUGO J. SCHIELKE ${ }^{\text {a,e }}$, WILLIAM B. STILES ${ }^{\text {a }}$, \\ RAVEN E. CUELLAR ${ }^{a}$, JONATHAN L. FISHMAN ${ }^{a}$, \\ CORINNE HOENER ${ }^{a}$, DARREN DEL CASTILLO ${ }^{\mathrm{b}}$, \\ APRIL K. DYE ${ }^{\text {c }}$, NOGA ZERUBAVEL ${ }^{\mathrm{a}}$, \\ DAVID P. WALKER ${ }^{a}$, \& LESLIE S. GREENBERG ${ }^{d}$
}

${ }^{\mathrm{a}}$ Miami University, Oxford, $\mathrm{OH}$

${ }^{\mathrm{b}}$ University of California, Santa Barbara

c Carson-Newman College, Jefferson City, TN

${ }^{\mathrm{d}}$ York University, Toronto, Canada

e Correspondence concerning this article should be addressed to Hugo J. Schielke, Department of Psychology, Miami University, Oxford, OH 45056.

Email: schielhj@muohio.edu

\begin{abstract}
The assimilation model of therapeutic change describes the self as comprised of multiple internal voices (mental states), and tracks the development of understanding and joint action between those voices in successful psychotherapies. This model has been constructed from studies of individual therapy, and has generally focused on intrapersonal change. The emotion-focused, couple therapy case presented here involving Sarah and Mark was studied using an iterative, team-based approach to theory-building case-study research to (1) assess whether the process of resolving interpersonal problems in couple therapy is isomorphic to the process of assimilation in individual therapy and, if possible, and to (2) extend the model's ability to describe the process of resolving interpersonal problems. Observations supported the hypothesis that intra- and interpersonal problems resolve in ways that are isomorphic to one another: The patterns of perception, emotion, communication, and action observed during the process of resolving interpersonal problems were consistent with those observed in intrapersonal problem resolution in previous assimilation model research. As the couple developed mutual understandings and increasingly engaged in cooperative action, previously excluded aspects of one another's experience came to be increasingly included (i.e., valued and influential) in each partners' meaning- and decision-making. This parallels the increasing inclusion of previously avoided experience observed in successful individual treatments. Case observations are presented, and clinical and research implications are discussed.
\end{abstract}

Key words: couple therapy; inclusion; exclusion; dialogical self; assimilation model; systems theory; clinical case studies; case studies 
A Case Study Investigating Whether the Process of Resolving Interpersonal Problems in

Couple Therapy Is Isomorphic to the Process of Resolving Problems in Individual Therapy

H.J. Schielke, W.B. Stiles, R.E. Cuellar, J.L. Fishman, C. Hoener, D. Del Castillo,

A.K. Dye, N. Zerubavel, D.P. Walker, L.S. Greenberg

Pragmatic Case Studies in Psychotherapy, http://pcsp.libraries.rutgers.edu

Volume 7, Module 4, Article 4, pp. 477-528, 12-12-11 [copyright by authors]

The systems theory principle of isomorphism (or "self-similarity") suggests that systems display similar patterns of process and organization across their various levels (e.g., von Bertalanffy, 1968). We investigated isomorphism between inter- and intrapersonal therapeutic change: We employed an iterative, team-based approach to theory-building case study research to examine whether the process of resolving interpersonal problems in couple therapy would be isomorphic to the process by which intrapersonal problems in individual therapy come to be resolved.

\section{INTRAPERSONAL DIALOGUE AND INCLUSION: USING INTERPERSONAL METAPHORS TO UNDERSTAND INTRAPERSONAL PROCESSES}

The principle of formal similarities between inter- and intrapersonal communication has long been influential (Stiles, 1997, 1999) in the development of the assimilation model (e.g., Stiles, 2002), a model of therapeutic change constructed mainly from observations at the intrapersonal level in individual therapy. Observations from individual therapies have led researchers elaborating this model (e.g., Brinegar, Salvi, Stiles, \& Greenberg, 2006; Brinegar, Salvi, \& Stiles, 2008; Honos-Webb \& Stiles, 1998; Osatuke et al., 2004; Osatuke \& Stiles, 2006; Stiles et al., 2006) to adopt interpersonal terminology (e.g., voices, community, dialogue, and inclusion) as metaphors to describe intrapersonal change processes, and to use these metaphors in describing the process of therapeutic change.

The assimilation model describes the self as a community of voices, where each voice is a mental state of the person and represents interconnected traces of a person's experience (Brinegar et al., 2006; Honos-Webb \& Stiles, 1998). This model notes that a person's different voices can take differing positions in relation to events. Such voices may be observed in the form of seeming discrepancies in the way a person speaks or acts at different times (Stiles et al., 2006), and may be experienced in the form of divergent wants and/or needs (e.g., "part of me wants one thing, another part, something else"). Finally, voices representing experiences or positions that are threatening or painful to a person's accepted views of themselves and the world are likely to be regarded as problematic.

The assimilation model's description of the self as consisting of multiple, interrelated parts is consistent with a number of models of therapeutic change anchored in a wide range of theoretical orientations (see, e.g., Rowan, 1990; Rowan \& Cooper, 1999), including interpersonal (e.g., Benjamin, 2006; Sullivan, 1953); constructivist (e.g., Hermans \& Kempen, 1993; Mair, 1977); family systems (e.g., Breunlin, Schwartz, \& MacKune-Karrer, 1992; Pinsof, 1995; Schwartz, 1995); cognitive-behavioral (e.g., Linehan, 1993; Young, Klosko, \& Weishaar, 2003); psychodynamic (e.g., Bromberg, 1998; J. Greenberg \& Mitchell, 1983; Watkins \& Watkins, 1997); process-experiential (e.g., Elliott \& Greenberg, 1997); narrative (e.g., Hermans, 2004); and integrative models (e.g., Ryle \& Fawkes, 2007). The assimilation model's emphasis on dialogues between different aspects of self links it with a family of explicitly dialogical models of the self (see, e.g., Hermans \& Dimaggio, 2004) that describe the self as consisting of multiple voices in dialogue. A feature of this model that makes it particularly suitable for exploring the 
question of isomorphism between intra- and interpersonal therapeutic change is that it offers descriptions of the process of successful problem resolution through the lens of attending to dialogues between intrapersonal voices.

In successful therapies, the patterns of relationship between problematic voices and the self evolve from unacknowledged presence through gradual emerging recognition to the eventual resolution of problematic experiences. This evolution is described in the assimilation of problematic experiences sequence (APES, see Table 1; Brinegar et al., 2006). The APES describes eight stages of progressively increasing self-understanding by the client (Stiles et al., 1990). Using the lens of the multi-voiced self, the APES also describes the unfolding of mutual understanding and acceptance between intrapersonal voices (Honos-Webb \& Stiles, 1998). It chronicles a process of assimilating, integrating (e.g., Brinegar et al., 2006, 2008) or including (Osatuke \& Stiles, 2006) a voice into the community of voices representing the accepted sense of self. This process yields more comprehensive and coherent narratives about the self (e.g., Osatuke et al., 2004; Osatuke \& Stiles, 2006; Ribeiro, Bento, Salgado, Stiles, \& Gonçalves, 2011), an achievement that has, in turn, been linked with psychological well-being (Baerger \& McAdams, 1999). Increasing APES levels have also been associated with more conventional measures of psychotherapy outcome (Detert et al., 2006; Stiles, 2006).

In short, research with the APES suggests that developing acceptance and understanding between intrapersonal voices (which emerges at APES 4, and is then increasingly applied in APES 5, 6, and 7) is associated with progress towards the resolution of problematic experiences. Conversely, the observations informing the APES suggest that a lack of mutual understanding and acceptance between voices is associated with experiences being defined as problematic. For example, at APES 1 (see Table 1), clients are seen to actively avoid voices representing problematic experiences, and at APES 2, a vague awareness of an experience regarded as problematic for the client's accepted understanding of the situation in question is associated with significant psychological pain.

\section{DO INTERPERSONAL PROCESSES FOLLOW A PARALLEL COURSE?}

Might the emergence and resolution of interpersonal problems in couple therapy follow a course parallel to the APES? Research on intimate interpersonal relationships appears to present some evidence that this is so. This research suggests that marital problems are associated with a lack of mutual understanding, and suggests that the problem-solving patterns most highly associated with divorce include: Being unwilling to engage in dialogue about the problem; being unwilling to legitimate the other's point of view; making globally negative statements about the other's person, reflecting an inability to see the other's perspective; and active rejection of and/or disgust in relation to the other's perspective and person (e.g., Carrere \& Gottman, 1999; Gottman, 1994; Gottman \& Levenson, 1999; Gottman., Coan, Carrere, \& Swanson, 1998; Gottman, Murray, Swanson, Tyson, \& Swanson, 2002; Markman \& Hahlweg, 1993; Matthews, Wickrama, \& Conger, 1996). 
A Case Study Investigating Whether the Process of Resolving Interpersonal Problems in

Therapies informed by this research (e.g., Catherall, 2007; Gottman, 1999; Greenberg \& Goldman, 2008) aim to create mutual understanding and reduce the presence of problematic relational patterns by helping couples empathically understand one another and learn how to engage each other in ways that are sensitive to each partner's esteem and relational needs. These therapies encourage non-defensive sharing of thoughts and feelings that underlie observable reactions. As part of this process, each partner is encouraged to be curious about the other's perspectives, and to try to see their interactions through their partner's eyes as well as their own. The creation of mutual understanding increases partners' sense of we-ness (partners' sense of identity as a couple and solidarity with one another (Gottman \& Levenson, 1999). Increases in partners' sense of we-ness have, in turn, been found to be associated with reduced indications of couple dissolution risk (Gottman \& Levenson, 1999) and increases in partners' relational satisfaction (Reid, Dalton, Laderoute, Doell, \& Nguyen, 2006). Increases in we-ness have also been associated with increased couple mutuality and increases in the degree to which the other is experienced as being included in a partner's sense of self (Reid et al., 2006).

In sum, just as a failure to include or assimilate the positions of intrapersonal voices is problematic for an individual, partners' failure to allow themselves to be influenced by their partner's positions is problematic for the couple relationship. Further, intra- and interpersonal problems come to be experienced as resolved as once-excluded positions become increasingly influential. These parallels suggested that the process of resolving interpersonal problems might be isomorphic to the process of resolving intrapersonal problems as described in the APES. We employed an iterative, team-based theory-building case study research process to explore this question.

\section{THEORY-BUILDING CASE STUDY RESEARCH: A BRIEF INTRODUCTION}

In theory-building case study research (Stiles, 2003, 2005, 2007, 2009), case material is studied with the intent of assessing and expanding a theory of interest. In this approach, theory is treated as an evolving, logically coherent framework for describing and explaining observations. Theoretical statements are subject to ongoing inquiry, and remain tentatively held, open to modification and elaboration based on additional observations.

Whereas statistical hypothesis-testing studies compare one theory-derived statement with observations on a limited number of variables across many cases, theory-building case study research studies compare many theory-derived statements with many observations within each case studied. Of course, little confidence can be gained in any one isolated statement by this approach. However, the cumulative increment in confidence in the theory as a whole from each case that matches theory in detail may be comparable to that in a successful statistical hypothesis-testing study (Campbell, 1979; Stiles, 2009, 2010).

The theory-building case study research process involves comparing the statements of a theory with case observations; observations that are not consistent with theory are seen as indications that the theory requires revision. Central to the success of this qualitative approach is the notion that an invalidation of any aspect of the theory is not regarded as a failure that is to be 
avoided. Instead, such instances are explicitly sought out and regarded as opportunities to further enhance the theory. In such instances, the theory is refined to account for new observations while maintaining its ability to account for observations consistent with previous formulations of the theory. It is in this way that observations can be said to permeate the theory (Stiles, 1993, 2003, 2007). Peirce (1958) described this process as that of abductionresponding to an observation that contradicts expectations by introducing or modifying a tenet of theory such that "if the new tenet were the case, then the observation would be expected" (Stiles, 2009, pg. 18).

\section{STUDY DESIGN}

Encouraged by the parallels between intra- and interpersonal problem resolution in the literature, we engaged in a theory-building case study to examine whether the relationships between interpersonal voices in successful couple therapy might evolve in a manner parallel to the APES' descriptions of the evolving relationships between intrapersonal voices in successful individual therapy. In part, this involved taking the assimilation model's metaphors literally. Instead of focusing on elaborating the APES' ability to describe the dialogue between a person's metaphorical inner voices, we studied video and transcripts of couple therapy to assess and refine the ability of this measure to describe interpersonal therapeutic change. To this end, we 1) took the stages and stage descriptions defined by the APES (see Table 1; Brinegar et al., 2006) as our point of departure; 2) modified the language to consistently use terminology applicable at the interpersonal level (i.e., re-cast all language through a lens focused on dialogue between voices and the inclusion and exclusion of voices' positions; see Table 2); and 3) studied and refined the ability of this theoretically extended model to describe the patterns of relationship reflected in actual dialogues between married partners in successful couple therapy. Isomorphism in interand intra-personal change processes was treated as a hypothesis that could be denied as follows: The hypothesis of isomorphism in the structure of inter- and intra-personal therapeutic change processes was to be rejected if the interpersonal behavior in successful couple therapy did not conform to a model that had a structure consistent with what has been shown to be true for intrapersonal changes in individual therapy.

\section{Method}

The examination of this potential isomorphism and the case observations presented in this article represent elements of a larger theory-building project; that project studied two successful cases and one unsuccessful case, and explored the possibility of developing a single theoretical framework to describe inter- and intrapersonal relational change. Although the present article restricts its focus to assessing the presence of isomorphism in the relational patterns observed in intra- and interpersonal therapeutic change-a prerequisite for creating the larger theoretical framework - it will include a description of the method followed for the larger study to clarify the basis for the theoretical elaborations, observations, and conclusions we present here. 
A Case Study Investigating Whether the Process of Resolving Interpersonal Problems in

\section{$\underline{\text { Participants }}$}

Cases. The case presented here, that of Sarah and Mark (pseudonyms), was one of two successful couple cases we studied as part of a larger project (Schielke et al., 2009; Schielke, 2010) aimed at exploring the possibility of describing the process of intra- and interpersonal change within a single theoretical framework. Cases were drawn from the Emotional Injury Project (EIP) at the York University Psychotherapy Research Clinic (Greenberg, Warwar, \& Malcolm, 2010). The EIP studied the effectiveness of 10-12 sessions of emotion-focused therapy for couples (e.g., Greenberg \& Goldman, 2008) for facilitating the resolution of a longstanding emotional injury sustained within their relationship. To qualify for the EIP, the emotional injury had to be identified as actively problematic, causing unresolved hurt or anger, and had to have been problematic for least 2 years. In addition, the couple had to have been cohabiting for a minimum of two years, and both partners had to express a desire to remain together. The screening process excluded potential participants who demonstrated evidence of partner abuse, substance abuse, suicidal ideation, or severe psychological disturbances (dissociation, psychosis, or narcissistic or borderline personality disorder) in either partner. The 20 couples included in the EIP were recruited through newspaper advertisements, and provided informed consent to participate.

The EIP judged both of the positive outcome cases studied as successfully resolved; this determination was based in part upon partners' post-treatment responses on the Enright Forgiveness Inventory (Enright, Rique, \& Coyle, 2000) in conjunction with post-treatment and 3-month follow-up interviews. The presence of meaningful therapeutic change was also suggested by the difference between the couple's pre- and post-treatment Dyadic Adjustment Scale (Spanier, 1976) scores, which reflected a significant reduction in the couple's levels of marital distress. (See Table 3 for the couples' pre- and post-treatment assessment scores; see Table 4 for a presentation of the EIP's observed means and standard deviations; see Greenberg,Warwar, \& Malcolm, 2010, for a discussion of the measures themselves and their use in the original study.)

Investigators. The principal investigator (PI), Hugo J. Schielke, was a male clinical psychology doctoral student in his 30s, and this project was part of his degree research. His graduate advisor, William B. Stiles, who consulted on design, implementation, and interpretation, was a male in his 60s and a professor in the program. The seven co-investigators on the research team-Raven E. Cuellar, Darren Del Castillo, April K. Dye, Jonathan L. Fishman, Corinne Hoener, David P. Walker, and Noga Zerubavel-were doctoral students in the same program; all were in their 20s or 30s. Each successful case was studied by four investigators (three co-investigators and the PI). Co-investigators were assigned such that each successful case was studied by one female co-investigator with no previous experience with the assimilation model and one female and one male co-investigator who had formally studied and/or researched the model. (David P. Walker and the PI studied an unsuccessful case from the EIP that will be presented elsewhere.) Co-investigators' self-identified primary theoretical orientations were cognitive-behavioral, developmental, existential, humanistic, interpersonal, psychodynamic, systemic, and third-wave feminism. Diversity in co-investigator gender and theoretical allegiance was sought with the intention of increasing the likelihood that salient case 
A Case Study Investigating Whether the Process of Resolving Interpersonal Problems in

information would be identified and attended to. This decision was also informed by the finding that the presence of dissenting positions prior to decision-making leads to better decisions (Schulz-Hardt et al., 2006). The director of the EIP project, Leslie S. Greenberg, was a male in his 60s and a professor in a different clinical psychology program. All ten of these people are authors of this paper.

\section{Procedure: Iterative Abduction}

The theory-building case study framework encourages an ongoing dialogue between theory and observations, but offers a great deal of freedom around how such a dialogue is structured. Inspired by the framework's ideals, our procedure aimed to maximize the likelihood that theory-divergent case data would successfully inform the ongoing development of the model. A detailed description of the iterative procedure we employed to study the case data (see Figure 1) follows; detailed examples of the kinds of case observations that formed the basis for all model refinement decisions will be presented in the results section.

Pre-iteration: Preparing the model for iterative abduction. To prepare for the iterative abduction process, the PI conducted a literature review of the elaborations of the model to date. This literature review included a search of the American Psychological Association's "PsycINFO" literature database on the phrase "assimilation model” as well as a review of a list of relevant publications provided by William B. Stiles (one of the originators of the model, and the researcher most consistently involved in ongoing model research). The PI used the results of this review to create an electronic document that organized what appeared to be the most up-todate statements of the model's theory into three sections: the model's view of the person, the model's conceptualization of therapeutic change, and the sequence of patterns observed on the way to the resolution of problematic experiences as described by the APES (the focus of the present article). The citations for each statement or set of statements (e.g., the Brinegar et al., 2006 version of the APES) were also included. The PI then ensured that all statements were phrased in language that enabled comparison with case observations at the interpersonal level; this generally meant ensuring that all statements were cast in such a way that they focused on the inclusion and exclusion of voices' positions (e.g., see Table 2 for the pre-iterative version of the resolution of problematic experiences sequence, or RoPES). In the interest of transparency and attracting additional critical attention, each of these changes was identified as a tentative elaboration of the evolving theory using the word processing software's formatting and commenting features.

Particularly salient for the present article, please note that the changes made to the stage descriptions in preparing the model for theory-building case study feedback and refinement (see Tables 1 and 2) were limited to: (1) using voice and inclusion/exclusion focused formulations throughout each of the stages' descriptions to ensure that the language used would make sense at the interpersonal level, and (2) in many cases, adding a brief description of the relational implications of the kind of utterances, relational stances, and/or actions that we expected to observe for that stage. However, also note that the descriptions of the evolving relationships between voices (i.e., the descriptions of each of the eight stages) remained consistent with the descriptions of the evolving relationships between intrapersonal voices as described in the APES 
A Case Study Investigating Whether the Process of Resolving Interpersonal Problems in

Couple Therapy Is Isomorphic to the Process of Resolving Problems in Individual Therapy

H.J. Schielke, W.B. Stiles, R.E. Cuellar, J.L. Fishman, C. Hoener, D. Del Castillo,

A.K. Dye, N. Zerubavel, D.P. Walker, L.S. Greenberg

Pragmatic Case Studies in Psychotherapy, http://pcsp.libraries.rutgers.edu

Volume 7, Module 4, Article 4, pp. 477-528, 12-12-11 [copyright by authors]

(see Table 1). Put in other terms, the patterns of relationship between voices described in each pre-iterated RoPES stage is isomorphic/self-similar to its APES counterpart.

Iterative theory-building process. Co-investigators were asked to review the video recordings and transcripts of the couples' sessions and specify how case material disconfirmed, supported, and/or could inform specific statements in the evolving model. In the interest of minimizing the well-known tendency towards confirmation bias (e.g., Nickerson, 1998), collaborators were explicitly encouraged to emphasize the search for theory-disconfirming information in their efforts. This request was intended to induce a critical norm for the decisionmaking process; such a norm has been shown to reduce the tendency to ignore disconfirming information in decision-making (Postmes et al., 2001). The principal investigator then attempted to elaborate the theoretical statements to address any discrepancies or deficiencies; elaborations were subject to the independent approval of each of the co-investigators.

More specifically, for each session: (1) Each investigator independently reviewed the video recordings and case transcripts and noted evidence that ran contrary to, was currently un(or under-) described by, or offered confirmation of the model-in-progress as elaborated. (2) Each investigator independently evaluated the current iteration of the model-in-progress based on the case data they had observed. This review process involved rating the descriptive accuracy of each of the model's theoretical statements in relation to the case material as well as adding comments and references to the data that formed the basis for their ratings. Ratings of each statement were made using a 7-point Likert scale ranging from 0 (the theoretical statement was completely invalidated by the co-investigator's experience of the case material) to 6 (perfect correspondence between observed data and the statement). Co-investigators were also encouraged to indicate instances in which they did not feel they had enough data to evaluate a statement. (3) The principal investigator then reviewed co-investigators' feedback and generated the next iteration of the model-in-progress. The refined model (including reasons for changes and requests for additional feedback) was then submitted for co-investigators' review alongside the next round of session data. (4) Regular meetings were held to ensure that coinvestigators' feedback was being accurately understood and successfully incorporated into the model, and to explore and address any procedural questions. This iterative process was repeated for each session of case material. Once all sessions had been reviewed, final phrasings of the statements capturing the study's observations were refined over three additional iterations.

\section{RESULTS}

Co-investigators gave each statement included in the final model a Likert rating of 6, suggesting that co-investigators experienced a perfect correspondence between the observed case data and the final formulations of each statement. Consistent with the systems theory principle of isomorphism, observations supported the hypothesis that the resolution of problematic experiences between partners in couple therapy evidenced a structure and sequence of relational configurations consistent with those identified in prior research on intra-individual therapeutic progress: Although the iterative abduction process resulted in refinements to each of the RoPES' eight stage descriptions and the addition of a sub-stage between stages 3 and 4 (to be discussed 
A Case Study Investigating Whether the Process of Resolving Interpersonal Problems in

below), the structure of the relationships described in each stage in the final version of the RoPES (see Table 5) remained consistent with the relationships betweeen intrapersonal voices described in the APES (Table 1) and the pre-iterated version of the RoPES (Table 2). In other words, all three versions describe isomorphic/self-similar relational patterns in each of the corresponding stages.

\section{Resulting Measure: The Resolution of Problematic Experiences Sequence (RoPES)}

The final Resolution of Problematic Experiences Sequence (RoPES; see Table 5) represents an elaboration of the Assimilation of Problematic Experiences Sequence (i.e., APES, Brinegar et al, 2006; see Table 1) aimed at extending the sequence's descriptions to apply to interpersonal dialogue. Developed by subjecting APES stage descriptions to scrutiny and iterative revision in relation to two cases of successful couple therapy, the RoPES describes patterns observed during the process of resolving problems between voices, and is used to track changes in the relationships between voices by attending to the positions taken (e.g, uttered) by each voice.

Each of the eight stages of the RoPES (numbered 0-7) represents an increasing degree of involvement and understanding between two voices, and describes a particular kind of relationship between those voices' positions. In a change from previous versions of the APES, each RoPES stage (e.g., RoPES 0, unaware / unheard) offers a description of the relational implications of a particular kind of utterance, relational stance, and/or action from both voices' frames of reference. The description in bold describes the state of the utterance's author; the description in italics reflects the relational implications of that same utterance for the other voice in question. For example, RoPES 2 is titled vague awareness / not understood; RoPES 2 utterances, then, suggest only a vague awareness of the other voice's positions, which, in turn, implies that the full implications of the other voice's positions are not really understood.

The ability of the RoPES to describe and track therapeutic change in couple therapy is demonstrated below in relation to observations from Sarah and Mark's case. The case observations and analyses presented below also offer data in support of the descriptions within the RoPES; this, in turn, demonstrates that case data supported the notion that the relational changes observed during the stages of change involved in resolving interpersonal problems in couple therapy conformed to the descriptions of relationships between intrapersonal voices derived from previous research on change in individual therapy. Although some comments will be offered on the partners' relevant intrapersonal changes, the emphasis of the observations and analyses presented below is on demonstrating the model's ability to describe interpersonal problem resolution and presenting observations supporting the descriptions within the RoPES.

\section{Case Overview}

(Note that identifying details have been excluded or modifed as appropriate for confidentiality purposes.) Sarah and Mark, married for 12 years, sought counseling in an attempt to address an emotional injury from an abortion decision that had been made more than 10 years earlier. At the time of that decision, the couple had a one year-old daughter and was about to 
A Case Study Investigating Whether the Process of Resolving Interpersonal Problems in

embark on starting a business. Mark insisted that the couple could not financially support another child, and expressed the firm opinion that Sarah should have an abortion. Years later, Sarah told Mark that she'd felt completely powerless to oppose him, and that she felt deeply betrayed by what she experienced as a unilateral decision. As Sarah put it in the second session, "the abortion seems to have been, like, Mark’s decision.”

The conversations in therapy came to link both partners' understanding of the presenting problem to a basic difference in how Sarah and Mark approached the world. Mark tended to almost exclusively emphasize logic in his decision-making; Sarah, on the other hand, placed a great deal of emphasis on her own and others' emotions. It became clear that the abortion decision represented an extreme example of how this mismatch played out in their relationship. This mismatch had developed into a recurring problematic cycle: Mark would ignore what he might refer to as non-rational context, leaving Sarah feeling invalidated, and Sarah would attack Mark for his lack of understanding. In response, Mark would defensively retreat to an intellectualized position, which resulted in Sarah feeling further invalidated, and so on.

Over the course of therapy, Mark took responsibility for being forcefully insistent during the abortion decision, and came to increasingly value both Sarah's and his own emotions. For her part, Sarah recognized that, although she had not been aware of it at the time, she had also played a part in the process. As a couple, both partners came to better understand the reasons for their own behavior, and learned how to engage in dialogue with one another in a way that respected the other's experience. These changes, in turn, enabled the couple to heal the rift between them that the abortion decision had caused.

As is true in almost every case, multiple areas of concern came to be discussed, and multiple changes in their relationship were evidenced. The case data presented below (observations from sessions two, three, four, six, seven, 10, and 11) were selected because of their relevance to the abortion decision.

\section{Session Two}

Sarah's Description of the Problematic Experience (RoPES 1; note that all references to RoPES below are to Table 5)

At the time of the abortion decision, Sarah did not feel like she had any say in the matter. Sarah angrily described Mark as "adamant" and "totally detached and cold... logical and cold, feeling-less.” Her sense of Mark's reaction to her pain was, "Oh, I saw that you were upset, but I thought that you could get over it.”

These quotes reflecting Sarah's memories of the problematic exchange suggest that, at the time of the abortion decision, Sarah experienced her positions as being ignored by Mark. Put another way, Sarah was experiencing her positions as being excluded from influence in Mark's meaning- and decision-making processes. Instead of feeling heard, valued, and understood, Sarah appeared to have experienced Mark as avoiding the implications and suppressing the influence of her positions, and ascribing different meaning to her reactions than she did. 
A Case Study Investigating Whether the Process of Resolving Interpersonal Problems in

Sarah's experience of Mark's behavior fits the description of RoPES stage 1, active avoidance, suppression, redefinition / ignored. The first part of the description (in this case, active avoidance, suppression, and redefinition) refers to the relationship of a voice (in this case, one of Mark's voices) to another voice's positions; the second (in this case, ignored) describes the relationship from the perspective of the other voice (in this case, one of Sarah's voices). Also consistent with RoPES stage 1, Sarah identifies Mark as the cause of the problem ("the abortion seems to have been... Mark’s decision”).

\section{Sarah’s Increasing Awareness (RoPES 2)}

The couple's therapist, a female trainee, invited Sarah to offer a more detailed description of her experience of the abortion decision.

Therapist: So it feels like 'I didn’t have a choice and, and then, somehow'

Sarah: $\quad$ Not really, no. No. Well - I don’t know, I just, I felt just like, you know

Therapist: Do you remember when you had the conversation with Mark about the abortion?

Sarah: Oh yeah. Yeah.

Therapist: Okay, and do you remember, sort of, what was said?

Sarah: Yeah. Oh yeah! I remember going to that movie (Therapist: right), I remember the bar that we were in, talking about it. Remember? (Therapist: mm-hm) (Mark: mm-hm) Mm. Yeah, I rememb- I don't remember, I don't remember any specific (two-second pause) words, but I remember how adamant he was (Therapist: mm-hm) and (inhales) I remember how upset I was. (Therapist: right, yeah)

Therapist: And did you tell him at the time that you were upset? I mean

Sarah: $\quad$ Oh yeah. Well, he could see it, I didn't think I had to verbalize, I'm sure I did, but (Therapist: mm-hm, mm-hm).

Sarah's answer suggests that her understanding of the situation was beginning to shift. As Sarah reflected on her experience, her description of the situation became less certain. The trailing off of the last line quoted also suggests the introduction of uncertainty into her understanding of the situation ("Well, he could see it, I didn't think I had to verbalize, I'm sure I did, but"). Such shifts in perception are consistent with the beginning of RoPES stage 2 (vague awareness). Sarah's impressionistic recollection of the events, her and inability to articulate "any specific ... . words" that were spoken — that is, the vagueness of her memories-is also broadly consistent with RoPES 2.

An important aspect of this stage is that the positions of a voice associated with a problematic experience are not understood. The pain associated with this inability to understand Mark's actions at the time of the decision became repeatedly expressed by Sarah. Earlier in the 
A Case Study Investigating Whether the Process of Resolving Interpersonal Problems in

same session, for example, Sarah had plaintively asked "How could someone who you love do something that would hurt you?" The delivery of this question was loaded with a sense of blame towards Mark.

\section{Mark’s Inability to Understand Sarah's Response to the Abortion Decision (RoPES 2)}

Curious about Mark's experience of the exchange, the therapist asked for Mark's understanding of Sarah's reactions to the abortion decision.

Mark: $\quad$ Well, I knew she was upset about it (Therapist: yeah) but I didn’t know (Therapist: mm-hm) that she was - that she was - okay, I mean (...) yeah, I mean, (Therapist: yeah) [I knew] that, that, that she was upset that it [the abortion] was going to happen (Therapist: mm-hm) um, but, that's different from being - um, so adamantly against it that she would say, 'no I'm, - there's got to be different, another way.'

In this passage, Mark appeared to be reporting that while he had been aware that Sarah had been upset, he had not understood that she was upset with how he had been interacting with her; instead, he experienced the cause of Sarah's distress as external to himself and his behavior. He also appeared to insinuate blame for not clearly representing her positions at the time of their discussion. Each of these qualities is consistent with RoPES 2 (vague awareness / not understood).

\section{The Couple Begins to Clarify Their Interpersonal Positions (RoPES 3.1 \& 3.3).}

This last statement of Mark’s immediately preceded a shift in the partner's interactions. Prior to this comment, the partners' conversation was generally funneled through and facilitated by the therapist. Immediately after this statement, however, the partners began a direct exchange between one another. In this exchange, each partner countered and implicitly and explicitly disputed the validity of the other's understanding of the situation.

Mark: (...) That's different from being - um, so adamantly against it, that she would say, 'No I'm, - there's got to be a different, another way.' Whatever, I mean, (Therapist: mm-hm) so

Sarah: [Incredulous] But there wasn’t another - what was the other way?

Mark: Well, I'm, I'm just, well, like you said, you, okay, you said you didn't feel so strong in the relationship that you could, you know, you just had a baby, so if you ah, didn't have the abortion and I was adamant about it, what would happen to our relationship. (Therapist: $\mathrm{mm}$ )

Sarah: [Angrily] Yeah, well, that's a big thing.

Mark: Well, you never explored that. 
In this exchange, both Sarah and Mark were actively advocating their view of the problem and disputing the other's account of the situation in question; this is consistent with RoPES stage 3.1 (rapid cross-fire / disputed). (Another way of describing this sub-stage is that, in rapid cross-fire, both voices are fighting to be heard.)

In response to Mark’s last statement ("Well, you never explored that”), Sarah appeared to be both frustrated and taken aback by Mark’s position.

Sarah: [Challengingly] What do you mean?

Mark: Well, you didn't say to me, okay if if, if it's a, you know, that 'I'm going to leave or, or, or I'm simply not going to have the abortion and you can, you know, decide what you want to do about it' (two-second pause) I- I mean [trailing off in response to Sarah getting upset and the therapist's response to this]

Sarah continued to listen to Mark as he stated his positions on the matter ("Well..."), positions that were clearly difficult for Sarah to hear (she became visibly upset as he continued). This kind of exchange is consistent with RoPES 3.3, listening / listened-to, tolerated. The couple's therapist took note of the degree to which Sarah had become upset, however, and asked Sarah to talk about this.

Therapist: So wh- what's happening, it seems like you're trying to push down a lot, like when I just, I’ve been looking at you, you were, (Sarah: deep inhale) just, just let the tears come, let's (10-second pause)

Sarah: $\quad$ (Deep inhale, crying) Well, now I feel like a, maybe the onus is b- being put back on me, that maybe, probably, I don't know, if I'd done something, then I wouldn't have had the, have had the abortion, but at the time I don't, didn't feel that I had any options. (Therapist: mm-hm) So I really am upset that, that I'm trying to be, be made to feel now that I did. (crying) (Therapist: right, right)

In this quote, Sarah asserted her positions while Mark listened; listening to Sarah required Mark to tolerate hearing Sarah assert a perspective that explicitly challenged his own without challenging her in response. This exchange, too, was consistent with RoPES 3.3, listening / listened-to, tolerated.

\section{Sarah’s Revelations and a Return to Rapid Cross-Fire (Ropes 3.1)}

Mark continued to assume this stance until Sarah made a statement he could not tolerate. This statement triggered Mark, and led to another sequence of rapid cross-fire.

Sarah: What would I, could, what was I going to do? (Therapist: mm-hm) Like, 'Okay, Mark I'm going to have this other baby without you, (Therapist: mm-hm) but we're going to live in the same house, and you'll still have your other son, but I guess you'll just ignore this child that I've decided to have with, you know, 
A Case Study Investigating Whether the Process of Resolving Interpersonal Problems in

that's, you know, your child, but you're not going to acknowledge it.' (Therapist: right). Like wel- (Therapist: mm-hm)

Mark: [Highly frustrated] Well, I mean, you're, but you're playing out scenarios that were never even discussed! (Sarah takes a deep breath followed by a threesecond pause) 'Well, we're going to live in this house, but you're not going to ackno- (Therapist: right) I mean, I mean, you’re you’re

Sarah: $\quad$ So, yeah, but I'm saying, you didn't come across that there was any option. (Two-second pause.) (Therapist: mm-hm)

Mark: $\quad$ Okay so if there’s no option

Sarah: $\quad$ Because I didn’t play out a whole script, (Therapist: mm) (Mark: Okay,) you didn't get it!

Mark: $\quad$ Okay, at the very least then, if, if it meant more to you than our relationship, then at, at the very least the option was [to talk about it].

Sarah: $\quad$ Oh, but you see, (Therapist: mm-hm) I had to make a choice. (Therapist: $\mathrm{mm}$ )

It bears noting that this re-emergence of rapid cross-fire seemed to erupt in response to Mark feeling like his perspective was being ignored ("you're playing out scenarios that were never even discussed!”). Put another way, the degree to which Sarah was excluding his positions seems to have been too much for him to tolerate. This observation is consistent with the theoretical statement that voices want their positions to be included (i.e., valued and influential) in relevant meaning- and decision-making; it is also consistent with the statement that getting stuck in or returning to an earlier RoPES pattern is an indication that not all relevant voices feel like they have been (or will be) heard.

The therapist then intervened by asking Sarah what she had needed at the time.

Sarah: $\quad$ Oh, (8-second pause) I guess it would've been nice if we could have discussed options. (Therapist: mm-hm) you know, if it wasn't so, you know, 'there are no real options,' basically, that's the way I feel. My not mentioning to Mark (Therapist: mm-hm), 'that's the way I feel,' mm, okay, so, it's like me saying to you, you know, 'I think this is green, and no matter what you say to me, it's always going to be green. (Therapist: right) You could talk to me you can tell me all your stuff but it's going to be green and that's it.'

Here again, the couple was interacting in a way that is consistent with the description of RoPES stage 3.3, listening / listened-to, tolerated: Sarah was again asserting her point of view, and Mark was once again able to tolerate and listen to positions that challenged his own perspective. 
A Case Study Investigating Whether the Process of Resolving Interpersonal Problems in

Mark's Increasing Intrapersonal Recognition With the Aid of the Therapist (Ropes 3.5 - 3.9); $\underline{\text { Sarah Attends (RoPES 3.5) }}$

The therapist then refocused the couple's attention on understanding Mark’s reactions, and asked Mark what happened for him when Sarah got upset.

Therapist: Wh- what, I'm just wondering, like when you, sort of, see she's- she is probably upset like at the time, right? (Mark: mm-hm) What happens for you when she's upset? I know you say it's hard for you to see that she's hurt.

Mark's response to this question did not initially address the question directly. Instead, he first described the couple's interaction pattern in a way that seemed to be a statement of their typical roles (“she's emotional... and I'm the one who's... 'cold and detached;'), a way that was respectful (RoPES 3.5) of Sarah’s positions.

Undeterred, the therapist invited him to describe his internal experience again, demonstrating her continued active curiosity around the matter. This time, Mark provided a brief confirmation of the therapist's earlier statement: "it bothers me," he confirmed. The therapist then offered a tentative interpretation.

Therapist: Yeah. And then [there's] also that, you know, you don't, sometimes you resent having to take on that role, and sometimes (Mark: right) you'd like to be able to be yourself and express what you're feeling, and I guess, I'm trying to sort of get a sense of what is happening un- underneath sort of a, outward, like trying to keep things calm and and rational.

This demonstration of the therapist's active curiosity and tentative recognition of Mark's positions is consistent with (RoPES 3.9; exploring / tentatively recognized); after having his positions tentatively recognized (as indicated by Mark’s “right”), Mark acknowledged a function of his focus on logic.

Mark: (...) obviously it's a defense, I guess, in some ways it's a defensive way of, of dealing with stuff, (Therapist: right, yeah) for sure.

The therapist remained actively curious throughout Mark's answer, and offered Mark signs of tentative recognition (Therapist: “right, yeah”) - both of which are signs of RoPES 3.9. Perhaps as a result, Mark went on to report recognizing a transgenerational pattern.

Mark: $\quad$ I mean, my father's like the most, you know, reserved logical engineer. His father's an engineer; logical, (Therapist: right, right) you know, I mean. And if you, if you lined up my son and me and my father and his father all together at the same age, we're indistinguishable, I mean, (Therapist: right) so, you know.

Although still not answering the therapist's question directly, Mark's having called attention to his family's transgenerational pattern can be said to have reflected a respectful (RoPES 3.5 attending / respected) stance in relation to Sarah's view of him as unemotional 
A Case Study Investigating Whether the Process of Resolving Interpersonal Problems in

(albeit one that remains focused on an "objective," intellectual understanding of the situation). Perhaps in response to the therapist's ongoing active curiosity (RoPES 3.9), however, Mark then returned to the original question on his own.
Mark: $\quad$ And, so, I mean, h- how, how do I feel below the surface? (Therapist: right) - (takes deep breath) - uh,
Therapist: Well, actually don't- what I want, ah, you know, just don't think about it so much, right? (Mark: yeah) I just, I mean, like when you used to hear her, and you sort of see her sadness around what it was like, I guess I'm wondering what, just, what do you, what happens, yeah, physically, like do you feel anxious, do you feel..?
Mark: Well sure, I mean at the ti- at the time, and even now, I mean (Therapist: mm- hm) anxiety, you know, some, some fear even of, of what's going to happen to the relationship um, um, ah, (four-second pause) guilt, (Therapist: mm-hm) you know.

This response suggested Mark had begun to open towards (RoPES 3.7) a vulnerable part of himself that both he and Sarah reported was typically excluded from his meaning- and decision-making. In addition, Mark's reference to "guilt" suggested that he was beginning to open towards Sarah's positions as well.

After briefly checking in with Sarah, who had been attentive throughout (RoPES 3.5), the couple's therapist returned the focus to exploring Mark's understanding of his behavior.

Therapist: I think that, you know, we carry with us, the family stuff (Sarah: Oh yeah! Unintentionally, it's there!) into other relationships. [You've said that] you come from a family where [focusing on logic is] the way you deal with, problems or emotions (...) maybe you could tell me a little bit more about that.

In the passage above, the therapist offered an invitation that included the modeling of a more self-empathic stance for Mark (a modeling that was reinforced by Sarah: "Oh yeah! Unintentionally, it’s there!”). Mark accepted this invitation.

Mark: Well, like when I was a kid, ah (Therapist: mm-hm) if I was in trouble I'd be the pleasing child (Therapist: mm-hm) trying to make light of it, um, be super accommodating. So, you know, I mean, in, in adult life, (Therapist: mm-hm, yeah) when I run into problems, I'm, you know, I try to; I'm not the sort of person who, when I get into a disagreement with someone - states their ground and says, 'This is it' like, (Therapist: mm-hm) you know. I'm like, you know, 'Well, how can we resolve this' and and so I'm sure it comes across as, um, (four-second pause) logical, because I don't like, I don't like confrontation. (Therapist: right) I mean I'm not at, you know, I mean, ah, I don't like aggressive behavior. I have a hard time dealing with, with it. And I think, so I think that in a lot of ways I was even more: cold and detached and firm.

Therapist: Sort of 'I don't want to get into telling her what I' 
A Case Study Investigating Whether the Process of Resolving Interpersonal Problems in

Mark: Because I didn't want to- I wanted to avoid any possible, any (Therapist: mmhm) chink in my armor would be seen as weakness, and (Therapist: right) then I'd, and then I would be

Therapist: attacked somehow into (Mark: right) it, you know

Mark: $\quad$ So, I mean (Therapist: mm-hm) I'm sure that I (...) probably came across as more - cold and detached and firm.

In this passage, Mark began to explore and tentatively recognize (RoPES 3.9) the intrapersonal dynamics that led him to present himself as "cold, detached, and firm." This tentative self-recognition did not represent an empathic understanding of Sarah's emotional experience in relation to his behavior; it did, however, lead to increased understanding of his own behavior. (It also confirmed Sarah's description of him at the time of the abortion discussion: she had described Mark as responding to her in a way that was "totally detached and cold... logical and cold, feeling-less, you know.”)

In exploring other relevant context around the time of the decision, the couple indicated that, at the time, Mark had been preparing to start his own business. Both Sarah and Mark indicated that this was a move that had initially been jointly welcomed. The therapist then asked Mark if he remembered his initial reaction to the news that Sarah was pregnant.

Mark: (Two-second pause) No. (Therapist: mm-hm) I mean I, you know, I could conjecture.

Therapist: Yeah, was there a lot of fear around it at the time?

Mark: $\quad$ Oh sure, yeah, I mean, it must have just been like, oh my God, you know, I could feel, the plan [to start my own business] slipping through my hand, and 'I'm going to become (Therapist: mm-hm) you know, like my neighbors' and ugh! You know. (Therapist: mm-hm) I don’t know what. (S: coughing) I’m sure, of some, - I don't know, yeah.

Therapist: Some, sorry, some- what? There must have been some fear? Is that what your saying?

Mark: $\quad$ Yeah, I mean, I-I'm sure, it was just (Therapist: mm-hm) like, you know, any, plans I had for where life was going to go (Therapist: mm-hm) were attached to the idea of starting the business and I'm sure that, that, - that I was in mortal fear of that, disappearing. (Therapist: mm-hm) For sure, I'm sure, I mean I, that! I remember (Therapist: mm-hm) it was like, you know, 'no this, this just can’t happen.'

In these turns, Mark increasingly recognized how his own intrapersonal reactions led him to interact with Sarah in the way she'd described. At the end of the session, he was able to state this even more directly.

Therapist: It sounds like there was a lot of stuff that was going on that both of you weren't aware of in the decision-making process. That you didn't talk about because there was the feeling of 'this is a choice (Sarah: mm-hm) that has to be made' 
Mark: I guess because of my (Therapist: right) reaction and, (Therapist: right) thinking that any discussion would, (Therapist: right) might lead to a decision that I was (Therapist: yeah) uncomfortable with, so, therefore, (Therapist: mm-hm) try to prevent all discussion.

In this turn, Mark openly recognized that he had, in fact, done his best to avoid any extended discussion of the abortion decision. In doing so, he confirmed another aspect of Sarah's description of him at the time of the abortion discussion (Sarah: "the abortion seems to have been... Mark’s decision”), and indicated that he was beginning to take responsibility for his part in the emotional injury that existed between himself and Sarah. He had not yet, however, understood how much he had hurt Sarah as a result of excluding her from influencing his meaning- and decision-making.

\section{Session Three}

\section{Sarah Clarifies Her Experience of the Problem (RoPES 3.5 - 3.9) While Mark Attends (RoPES} 3.5).

At the beginning of session three, Sarah asked the therapist about the need to take responsibility for her own role in the decision-making process.

Sarah: $\quad$ Do I have to take ownership of the fact that, even though at the time I felt like I didn't have much of a choice, and - the, I have to take ownership of my choice, that it means I did, it was my decision in the end, right?

The beginning of Sarah's question implies a not fully welcomed recognition that, regardless of Mark's actions, she might have responded differently, a position that also reflects an increasing regard for a point Mark had made (i.e., that she hadn't shared her thoughts on the matter with him). Such a stance is consistent with RoPES 3.5 (attending / respected). (It bears noting, however, that Mark’s position here, while true, was also self-serving; as he admitted, he hadn't wanted to hear a perspective different than his own at the time.)

The last part of Sarah's question suggests a tendency towards taking on too much responsibility for the decision, however ("it was my decision in the end, right"). This statement suggests that Sarah might have had a tendency towards excluding her own positions; this point would continue to become more salient in the therapeutic process. (The therapist, for her part, deflected the question.)

A bit farther into the session, Sarah returned to the process of clarifying why the experience continued to be painful for her.

Sarah: The whole ordeal is that, you know, his view of it, you know, to this day still is (two-second pause) different than what I wanted to happen. (Therapist: mm-hm) And I guess I just want to understand better why he would be, be so adamant with that (two-second pause) that was the right decision at the time or two years later and two minutes later, or today, whatever. 
A Case Study Investigating Whether the Process of Resolving Interpersonal Problems in

Therapist: Right. So, would you say that 'it's hard for me to forgive that you were so adamant about it?'

Sarah: (Sigh) Yeah! There has been a point that, at the time there was just, you know; maybe Mark looks back and sees it differently, but I - there was no give. Like I said to him, since that - episode there has never been another instance in our life where he has been so adamant about it, like, you know, about any other major decision

Therapist: $\mathrm{Mm}-\mathrm{hm}$, so (...) this is the one thing that stands out

Sarah: $\quad$ Yeah, (Therapist: mm-hm) like, everything, well, yeah. I think, well, maybe I've changed since then and maybe the reason he doesn't seem as adamant is because it's more me than him.

In this exchange, Sarah's statements suggest that Mark's continued exclusion of her positions around the abortion decision was what was making the experience an "ordeal." She also openly indicated that she still did not understand Mark's responses to her, particularly in light of what she experienced as typical of him. Finally, the last statement quoted also shows an increased sense of her own responsibility in the matter (while perhaps also indicating a tendency to take on too much responsibility). Consistent with RoPES 3.5, each of these statements reflect a respect for Mark’s positions.

Shortly thereafter, with the help of the therapist's ongoing active curiosity (RoPES 3.9), Sarah was able to further clarify what was problematic for her.

Therapist: What does it mean to you that he was so adamant about the position and he hasn't, and that's not his personality, or that's not, how you find him in your relationship

Sarah: Well, I guess I'm just trying to understand why! With that he was so - adamant in other things (low talking) that happened he hasn't been as adamant

With the benefit of the therapist's tentative recognition of her positions, Sarah continued this exploration.

Therapist: That's hard to let go of. How could this person who supports and loves me

Sarah: $\quad$ Exactly! It always comes back to that. (Therapist: mm-hm) how could, you know - like Mark is the kind of person who I'll say 'honey I want to, you know do this' "we'll if that's what you want to do I think that's great, if that's what you want to do.” Mark's never been like, held me back from anything! (Therapist: mm-hm) - but that one thing (two-second pause) so

Therapist: (Three-second pause) Mm-hm, so when you think about it now, (Sarah: mmhm) I mean I know that you're trying to be reasonable and trying to, you know, not to lay blame, but how do you feel: with respect to that towards him. Do you feel angry? Do you feel hurt? 
A Case Study Investigating Whether the Process of Resolving Interpersonal Problems in

Sarah: $\quad$ (Six-second pause) Um, well angry, hurt, deceived, yeah.

Therapist: So what, what, you know, 'I feel deceived that' what? That you - ?

Sarah: (Eight-second pause) Basically, if you really love someone you wouldn’t put them through that, if you saw that (sigh) - the person (Therapist: mm-hm) even of, prior to, during, after would be in so much pain. You just don't do it. And, like, I'm not sure I can (voice cracks) forgive him for making me do it.

In this exchange, with the aid of the couple's therapist, Sarah explored her experience of the implications of the abortion decision (RoPES 3.9) and came to the tentative recognition that she wasn't sure she could forgive Mark.

Therapist: Mm-hm. Can you look at him and say that to him now? (Five-second pause) 'I can't forgive you for' - right now

Sarah: $\quad$ (Three-second pause) Nope.

Therapist: So what happens then, when just now I asked you to look at him

Sarah: $\quad$ Well instead of, instead of getting angry and mad now I'm getting upset. (Crying) (Therapist: mm-hm) It's easier to get angry and mad.

Therapist: Yeah, yeah, it covers up the hurt that's underneath (Sarah: Yeah) and you realize it's part of; (Sarah: sigh) can you say some more about what that anger is covering up inside

Sarah: $\quad$ (Three-second pause) I just wish he could, right now I just wish that he could experience what I experienced, (Therapist: mm-hm) (two-second pause) (sniffles) the whole process

Therapist: Mm-hm. So it’s like 'I really need you to understand what it was like for me'

Sarah: Well yeah, (Therapist: mm-hm) like, I try to describe it but (sigh) (three-second pause) it's not the same. (Sniffles) (Therapist: mm-hm)

This exploration process, then, led to a clear statement of the current state of the problem-Sarah needed Mark to understand her experience. Sarah also clarified that she had a hard time expressing her concerns around being able to forgive Mark directly to him; Sarah's difficulty directly expressing such concerns to Mark (and the reasons for this difficulty) would come to be explored in greater detail in session four (see below).

\section{Mark’s Inability to Understand Sarah’s Experience (Ropes 3.5 Interrupted By Exclusion)}

Throughout this exchange between Sarah and the therapist, Mark was respectfully attentive (RoPES 3.5), and Sarah's words had clearly had an impact on him. The couple therapist invited Mark to share his reaction. 
A Case Study Investigating Whether the Process of Resolving Interpersonal Problems in

Therapist: Mm-hm, so what happens for you when you sort of, like, just right now! What's happening?

Mark: (Sigh; four-second pause) I, I feel guilty, but I mean, it's tempered by the fact that (two-second pause) like I said, you know, I feel guilty for the outcome, but not so much for the decision, like when she says

Therapist: Right now

Mark: When she says

Therapist: When you see her, that she's

Mark: $\quad$ It upsets me for sure, I mean (two-second pause) but it's such a; I'm so powerless to do anything. So it's such a frustrating -

Therapist: Right, so it's like 'I just don’t know what to do (Mark: yeah) I see that you're hurting and (...) 'I feel like there’s nothing that I can do.' (Mark: mm-hm)

[Turning to Sarah] I mean, given that we can't, you know, sort of, change bodies around and have him really you know, experience exactly what you experience, I think it's important (...) to really go into sort of $(. .$.$) what it was like for you.$

Here, Mark demonstrated a partial inclusion of Sarah's positions while also maintaining his original stance ("I feel guilty for the outcome, but not so much for the decision"), and shared a sense of confusion about what he could do to make things better. Consistent with RoPES 3.5, a broader range of affect is becoming evident.

Maintaining support for Sarah’s request for Mark to understand her, the couple's therapist invited Sarah to continue to share previously unshared experiences. With that, Sarah began to describe a number of thoughts she'd had since the abortion, focusing largely on what might have been if the two had gone through with the pregnancy. Mark remained respectfully attentive throughout.

The therapist then turned to Mark.

Therapist: What sort of happens for you, just, like, at a feeling level, when you hear her?

Mark: Like, it's it's just it's like crazy talk to me (Therapist: yeah) (...) I mean, what it comes down to, it basically is, ah, is, ah, it's very hard for me to be (two-second pause) have an emotional (Therapist: right) response when someone talks like that because it's just, it's they're speaking a foreign language.

Therapist: Mm-hm, it’s like 'I can’t relate to it, it feels kind of like, I don’t know, ridiculous or something

Mark: $\quad$ Sure! It, it’s fantasy world, you know, like 'oh you know it could have been this or it could have been that.' 
A Case Study Investigating Whether the Process of Resolving Interpersonal Problems in

In short, despite having given Sarah his respectful attention throughout her description of her experience and listened without interrupting her (RoPES 3.5), Mark was unable to connect with Sarah's perspective. Mark made it clear that imagining "what might have been" made no sense to him whatsoever, and that he had difficulty connecting emotionally with such imaginings. Although his reflective stance suggested that he did not mean his comments to be hurtful, Mark was clearly devaluing important aspects of Sarah's experiences related to the abortion decision.

\section{Trying to Help Mark Understand (RoPES 3.5).}

The therapist turned her attention to Sarah and invited Sarah to share her reaction to Mark's comments.

Therapist: Mm-hm, mm-hm. Okay, so what then happens for you [Sarah] when you hear this is his response?

Sarah: Well, like you know (laughs) if it was some statistical data! (Therapist: mm) I'm sure he would be more interested in that sort of thought (laughs)

Therapist: So you feel like

Sarah: Like I have to give him odds or numbers or something but you know, because [if] that's not the case, then that's just not the way it works. That's just not the way it works.

Although Sarah made a joke in response, her delivery made it clear that this was bitter humor. The couple's therapist encouraged Sarah to share her underlying reaction.

Therapist: Right, right. So what's the impact that has on you?

Sarah: Well, it's just, that just feeds into the not understanding my point of view. (Therapist: right) um (three-second pause) Mark, sometimes when he gets like this; his dad does it too, it's really um - um

Mark: (Whispers:) Condescending (Sarah: huh?) (Whispers:) Condescending

Sarah: Condescending, yeah.

Therapist: You feel sort of patronized a little bit

Sarah: $\quad$ Yeah, it's like I've seen it, patronizing, yeah. It's like 'oh look the you know, the hysterical female, the emotional female, must be her hormones, you know blah blah blah'

Therapist: Right, right.

Throughout these turns, the couple's therapist seemed to be trying to keep both members of the couple focused on a non-defensive discussion of the process between them ("So what's the 
impact that has on you?"). Mark's word suggestion (“Condescending”) could be interpreted in a number of ways: as an indication that he was beginning to understand Sarah, as a sign of his perceived intellectual superiority, or, perhaps both.

Mark: I don’t actually say that.

Sarah: No, no. (Therapist: mm-hm) But that's the impression, that's, you know, the read between the lines.

Therapist: And so, does that get you sort of more frustrated, or angrier, or what?

Sarah: $\quad$ Well, yeah (Therapist: mm-hm) that's sort of um - you know, um, what's the word I'm thinking of? Uh, (sigh) you know, I feel I have a point, and I have a stand that I have, and, and that put me down kind of thing, it makes it seem like I'm being irrational, or my point of view isn't, uh, um, right (Therapist: mm-hm) or - you know. If there's me and him in conversation, then you know that that's going to be the response. (Therapist: right right) Mark will say, you know, 'Well we haven't talked about it that much.' Yeah, well, that's part of the reason. (Therapist: mm-hm) When I know there's not going to be any sympathetic ear or understanding - Sometimes, yes, like, Mark, you can’t fix it, but - you know, you can listen without being - condescending.

Therapist: Right. So part of, I guess, this is what you need from him: 'I need you to listen.'

Sarah: $\quad$ But I don't think I'm ever going to get that. (Therapist: mm-hm) I mean like (Therapist: right).

In these turns, Sarah can be said to have clarified that she had her own positions that she wanted to be heard ("I feel I have a point"), as well as what kept her from sharing her underlying positions with Mark (his tendency to devalue them and exclude them from his own meaningmaking process; i.e., "When I know there's not going to be any sympathetic ear or understanding”). Through confirming the interpretation offered by the therapist, Sarah offered Mark a statement about what she needed and how he could meet that need ("'I need you to listen'”). Finally, Sarah also indicated that she was afraid that she might not be able to get that need met. Once again, Mark remained attentive throughout. The therapist then tentatively offered another way of looking at the problem.

Therapist: Maybe this is the impact of your [family of origin experiences]. (Sarah: yeah yeah) like there's, I mean it has to do with you know, two different styles of, you know, being based on your upbringing and personalities (Sarah: yeah yeah) and um, and so you [Sarah] feel, I mean, underneath all that anger is a lot of hurt that it doesn't feel like it's somehow safe to be expressed because 'what's the point if it's not going to be heard?' And then, um, when you do express something you [Mark] feel like it's hard not to feel attacked, and you feel like you need to defend yourself, and then you feel like - frustrated 'I can't - like what's the point,' and you [Sarah] get angry again and then you [Mark] start to go rational and try to figure things out and - I guess the question to ask you [Mark] is, what would you need to feel less blamed in all of this? 
A Case Study Investigating Whether the Process of Resolving Interpersonal Problems in

Mark: (Eleven second pause) Hmm. I don't even know if that's necessarily an issue, like (Therapist: right ok) like, I mean, I'm willing to accept responsibility for it, I'm not saying that I don't want to necessarily feel blame, I mean sure, (Therapist: right) it would be great if that went away, (Therapist: yeah I guess because) but on the other hand, what would be, what I would feel more relief from would be if there was some sort of getting beyond the point where we're at now, where I mean, yes, I can understand, like, to sense we don't talk about it, and we don't talk about it because of the way that I am, there's no disagreement I mean, (Therapist: mm-hmm) but on the other hand I don't think its going happen by - putting up a front of being somewhat (Therapist: no no) not, so I mean, it's really, it seems extremely complicated to me. (Sarah: Yeah.)

Mark's response indicated an increasing recognition of the role his interaction style played in perpetuating the problem ("yes, I can understand... [that] we don't talk about it because of the way I am”). It was also consistent with an approach to problem-solving that devalued emotional experience: put into other words, it was as if he'd said "it doesn't matter if I feel blamed - what matters is that we keep having this problem, and I don't want to just pretend it away - I want to fix it.” The couple’s therapist responded as follows.

Therapist: Well, I guess the thing is, is, that what I see is that, she [Sarah], in her frustration, you [Mark] feel blamed, and when you feel blamed, it's hard for you to be empathic or understanding because you feel like you need to defend yourself; and also, I think when you see her upset, you feel anxious and just (Mark: yah) a little (Mark: I’m sorry yah) And, (Mark: [unintelligible]) I mean when you [Sarah] see someone I mean just that's [Sarah, reacting to Mark, giggles] that's defending himself, or you know, saying, 'well I made the right decision at the time' it's really hard to open up - that I understand, I understand that. When you [Mark] feel anxious, it's sort of hard for you, this is the way that you deal with, um, things that feel out of control, or emotional experience (Mark: right) in your family of origin, that was the issue, so it's not, you know, to make you feel or say anything that you don't mean, but it's just more of a rather than trying to get you to be defensive, getting you to sort of hear what she's saying, and having her feel comfortable enough and safe enough to feel like she can say it (Mark: $\mathrm{mm}$ ) that's sort of what we're trying to get get past (Mark: right).

As indicated by Mark's signals of agreement throughout, with this renewed attempt on the therapist's part, Mark seemed to feel like his positions were reasonably well-recognized by the therapist (at a level probably best rated at RoPES 3.9 given what appear to be approximations of insight); he also seemed to take in the therapist's point. 
A Case Study Investigating Whether the Process of Resolving Interpersonal Problems in

\section{Session Four}

Sarah Shares Her Fear of Damaging Their Relationship (RoPES 3.9)

Sarah's difficulty in expressing positions that might threaten the couple's relationship emerged as salient at the time of the abortion decision (she didn't explicitly share her positions with Mark). She explored this difficulty in session four.

Sarah: $\quad$ I just feel like he, I feel like when I tell him this stuff how I feel it - it’s like tarnishing this relationship, you know, that we have had, or something (voice cracks) 'I can’t believe you felt that way all these years that I didn't know' so it makes him like

Therapist: So what's the sadness, then, when you say that?

Sarah: $\quad$ Well, ah, (crying) why can’t I just be me! Can I have this and not have to worry that it's ruining our relationship?

In these turns, Sarah was interpersonally voicing an intrapersonal struggle: taking both Mark's and her own perspectives into consideration, Sarah was struggling with herself around how to proceed (an excellent example of verbalized intrapersonal dialogue with a voice representing another person's positions). In response, the couple’s therapist encouraged Sarah to continue to explore her own experience. The two questions that emerge for Sarah present fairly clear statements of the concern that keeps her from sharing potentially relationally-threatening statements with Mark (“[W]hy can’t I just be me! Can I have this and not have to worry that it's ruining our relationship?”). Later in the session, Sarah returned to this point.

Sarah: I guess what I'm really wanting right now is I'm really wanting to just let stuff out (Therapist: mm-hm) and I'm really hoping that Mark is not over-analyzing it (Therapist: mm-hm) and, and just takes it for what it is (...) that's part of the reason why I was thinking maybe I don't want to do this. (Therapist: mm-hmm) it's because I don't want to (two-second pause) I don't want to damage a, a good relationship (Therapist: mm-hmm) I want the relationship to go forward and I'm just doing this because I thought it would help, maybe it would help me more than it's going to help you, Mark, in the end. But then I am the one who had the abortion, so (Mark: mm-hm) you know, so

Therapist: Can you tell him what this relationship means to you then?

Sarah: $\quad$ Everything is our relationship. (Seven second pause.) We're planning out our future together now, what we're going to do, and everything. I don't want to ruin that (voice cracks).

Therapist: 'I don’t see my life without you'

Sarah: (Crying) No! 
A Case Study Investigating Whether the Process of Resolving Interpersonal Problems in

In these very moving turns, Sarah made it clear that she recognized how difficult it might be for Mark to hear how much he'd hurt her (RoPES 3.9), voicing a concern that sharing her own positions might put a relationship she values so highly at risk. Throughout this process, the couple's therapist encouraged Sarah to continue by letting Sarah know that she was following her ("mm-hmm"); the therapist also encouraged Sarah to share her unspoken feelings with Mark and offered tentative formulations of Sarah's positions (RoPES 3.9) that seemed to resonate deeply with Sarah. As a result, Sarah shared just how important he and their relationship were to her ("Everything! is our relationship!”). (In the language of the model, Sarah was letting Mark know that he was included in her sense of self.) Consistent with RoPES 3.9, Sarah is demonstrating reflexivity ("maybe it would help me more than it's going to help you") as well as representing her own needs ("But then I am the one who had the abortion, so").

\section{Session Six}

Sarah Allows Herself to Share Her Hurt Directly; Mark Softens and Empathically Understands (Ropes 3.7 Through 4).

Two sessions later, Sarah allowed herself to "let [the] stuff out."

Therapist: Could you tell Mark a little bit about the void? And [to Mark] I just want you to listen, no judgment, and [...to try to put] it in your own words, what you think she is feeling. And so [Sarah], can you tell him about the void?

Sarah: (Sigh) um (four second pause) well (two-second pause) sort of, imagine something that you think about everyday (two-second pause) but there is nothing that you can really, can do about it but (crying) it's

Therapist: 'So I think about it everyday,' (Sarah: yeah) Mm-hm

Sarah: (Three-second pause) So

Therapist: Mm-hm, what's happening for you?

Sarah: (Crying) It's harder than I thought. I thought maybe by not crying that [unintelligible] (Therapist: mm-hm) [unintelligible] this feeling would've been but yeah, there's a lot of pain. (Therapist: yeah)

Therapist: Mm-hm, [and] some frustration that it’s still there (Sarah: yeah) but I think, I don't expect you; I'm not surprised, right, because you never really dealt with it, but you know, this is what we are trying to do now.

Sarah: $\quad$ I know, but I was equating (Therapist: yeah) dealing with not crying (Therapist: mm-hm) (four-second pause)

In other words, Sarah had been excluding her own feelings (positions) around the abortion, a response that had kept the experience from resolving. 
Sarah: Well, because um, the void is just that, that sort of feeling, like, on a daily basis that, you know, to some degree, something is missing (Therapist: mm-hm) (twosecond pause) that can't be filled (Therapist: mm-hm) really, truly. - And um, you know, feeling it affects - decisions you make, or the way you react in certain situations that are, I don't know

Therapist: So can you just like, 'it’s sort of how I react.'

Sarah: $\quad$ Because yeah, it's not tainted but (two-second pause) tempered by that feeling (two-second pause) you know you might just uh, like I know this is a very simplistic example but you know, just the fact that I get so upset quite often and [our daughter] always wants a friend over, and to me that is a constant reminder that she could have had a sibling but she didn't. (Therapist: yeah) So, obviously, that's not the appropriate reaction (...) but unfortunately it takes that very simple thing.

Therapist: Overreaction to the situation.

Sarah: $\quad$ Overreaction yeah, because uh (two-second pause) because of this ongoing feeling.

Sarah began to describe more of her experience. Clearly moved, Mark then began to show approximations of an empathic understanding of Sarah's experience (RoPES 3.9).

Sarah: $\quad$ [... and I rehearse] what could I have done differently? What could I have said to Mark (Therapist: mm-hm) that would made the situation differently?

Mark: $\quad$ Even though there is nothing! Everyday you know the answer, (Sarah: yeah) you go through the (Sarah: doesn’t matter) ritual exercise everyday of of, almost reliving it, (Therapist: mm-hm) in a sense...it's not something that you forget about for a week or you know you, sometimes say 'well you know, - well whatever' I guess every time you think about it, you think of it in terms of regret, powerlessness, re-living the moment, what could I have done differently? (Therapist: mm-hm) So all the things that, it's a pretty, it's big in a sense that is not something that, you know like

Therapist: Are you saying that about what she is saying?

Mark: $\quad$ Yeah, I didn't really (Therapist: right) imagine that it was such a big thing. I mean, yeah, I know we are here, and we are here to deal with it, (Therapist: right) but somehow, I guess (...) even when I thought it was a big thing before, not a big thing like that! (Therapist: mm-hm) You know? A different kind of big thing. (Therapist: mm-hm) Big in a sense that, like the biggest thing, like this sort of, you know, those kind of - bigger-than-life regrets that people have, (Therapist: right) where they did something, whether it was an accident, (Therapist: mm-hm) or something happened to them. (Therapist: mm-hm) That kind of 
A Case Study Investigating Whether the Process of Resolving Interpersonal Problems in

Therapist: And do you realize that that's in that category for her?

Mark: (Three-second pause) Just now.

This exchange was first example of Mark expressing what appeared to be approaching an empathic understanding of Sarah's hurt. When the therapist asked Mark to describe what he was feeling, after a 30-second pause, Mark responded that he felt:

Mark: Well, I guess a, kind of a powerlessness. (Ten second pause.) I feel like, kind of confused right now, (Therapist: mm-hm) just kind of, not really (two-second pause) so I don't know! Yeah shocked almost. I mean I guess (four-second pause) surprised of my own (two-second pause) misunder- not misunderstanding but sort of lack of, of not really getting it before and then not (Sarah coughs) (four-second pause) not really (two-second pause) guess I just didn't - see the sadness of it because that wasn't what was

Therapist: being presented to you necessarily?

Mark: $\quad$ Yeah, yes.

Mark's description of this experience indicated that seeing Sarah's hurt had led him to open toward (RoPES 3.7; softening / opened towards) Sarah's positions, enabling him to tentatively recognize (RoPES 3.9) and then empathically understand her experience. Consistent with RoPES 4 (insight / empathically understood), Mark's affect was powerful and mixed, and was accompanied by a recognition of having contributed to the problem.

The therapist then shifted her focus on Sarah.

Therapist: Mm-hm, mm-hm. what is happening for you?

Sarah: $\quad$ Well, I'm trying to figure out what my role was in his misunderstanding. (Therapist: mm-hm)

Seeing Mark soften towards her appeared to lead Sarah to soften towards Mark as well; in the quote above, Sarah began to become reflexive, a move consistent with a shift to RoPES 3.9. The couple's therapist, however, encouraged Sarah to continue to share more of her experience around the abortion decision directly with Mark.

Sarah: (Sighs) Well, yeah, uh, I feel that, I you know, your actions - were very contrary to, uh, your actions on many other things, that we've gone through, or whatever, you know, I, I see them somewhat, like, I know what you said originally, that, you know, this was all very new for you - you were just being a father for the first time, you were starting your career and everything, blah blah blah blah, but I see it all as very self-serving. And I think your choice not to see, I think your, I think you not seeing my pain, even though you say that now, you know, I think 
A Case Study Investigating Whether the Process of Resolving Interpersonal Problems in

it was a choice for you; I think you made a choice not to see it. I think it was always there, I think you chose not to see it.

The therapist quickly interjected herself.

Therapist: So, okay, so I just, I'm going to try [to slow things down] because I think that, this is sort of- we get stuck here sometimes. [...Without getting into attack and defense mode,] what happens for you [Mark] when you start to hear, some of what she's saying?

Mark: Well, I think the reason that I didn't see it as - pain, and sadness, was because I saw it as - anger and, blame, like, they [pain and sadness] were, so overwhelmingly rare, that it [anger] totally masked [them]

Therapist: So, what, in this moment, then, do you feel your walls going up?...

Mark: $\quad$ No, not really.

Therapist: Okay (three-second pause)

Mark: $\quad$ I mean, I've (Therapist: mm-hm) heard it (Therapist: right) before, I mean I know, that, now it's tempered with this kind of, (Therapist: mm-hm) revelation that (two-second pause) so I mean I can understand how she could say, you know, it's self-serving you did all these other things, you know, you just wanted to look at it this way, well, I could understand why she would think that that's the case, I mean

Therapist: Can you tell her that you can understand why?

Mark: I could, I can totally see why you would think that - that I was totally harsh and, and didn't, feel any empathy or sympathy or (Therapist: mm-hm) wasn't there, I (three-second pause) you know, I ...

The couple’s therapist's “Okay” seemed to suggest that she'd been taken off guard by how quickly Mark had seemingly begun to apply (RoPES 5; working through / applied) his new-found, hard-won understanding - an understanding that, while welcome, was bittersweet for Sarah, as she soon thereafter shared.

Sarah: $\quad$ Um - (crying) Well, I just wish that we could have, that we shared this like, years ago $(\ldots)$

Therapist: So tell him, I need, I needed to, look at him and tell him, 'I really needed'.

Sarah: $\quad$ Well, I really needed you back then, Mark, (Therapist: mm-hm) but I'll take now, as opposed to, nothing (sniffles). 
Sarah continued to share long-unexpressed thoughts and feelings with Mark. Asked to comment on the process, Mark noted that he was "more comfortable with this" than the couple's usual cycle.

Mark: $\quad(. .$.$) at the beginning, when you said 'okay, I want to delve into this' I'm$ thinking 'Oh my god, you know, am I ready for this?'... It's going to be, you know, (Therapist: mm-hm) 'you did this, you did this' (Therapist: mm-hm) and it’s just, totally not what I (Therapist: mm-hm) expected.

Sarah: It's totally not what I want; I don't like being the attacker (Therapist: yeah) and he being the, and that's, when you describe it that way, it's very (Therapist: yeah, but I don't mean it like) right, I know! But it's okay, I know what you're saying, I know it's true, (Therapist: right, mm-hm) but I'm just saying I don't like the d- d- description. (Therapist: mm-hm) I mean, that's certainly not something I aspire to in a relationship (Therapist: mm-hm) - And th- that it's, like, uh, you know, as much as, I was scared that Mark wouldn't like this part [seemingly referring to her more vulnerable side of herself], (Therapist: right) probably it's obviously better than the being the defender part.

Therapist: Mm-hm, so you're, can you say that, that it's like some kind of, what? Reassuring to hear you or, I mean, what is it that you're, what is your experience of hearing her sadness then?

Mark: (Three-second pause) Well, I guess I never imagined that I could feel sympathy - to the attacker - part, of the equation, I mean, I can certainly feel sympathy, now to the, to the way you are now, and, how you are affected, and I can only, I can imagine how invalidating it was, because I can imagine what I would have said. I would have said 'well, it's all for the best' but since then, I know that it's just been like, totally the wrong thing, to have said at the time so but I understand how you, quickly, gave up (Therapist: [incomprehensible]) talking to me about it.

Here, Sarah and Mark each indicated that they share an empathic understanding (have created a meaning bridge) around the problematic cycle they'd been experiencing; in particular, each indicated recognizing how they have been contributing to the problem. Mark also reported recognizing that, in fact, there was something he could do to help in such situations.

Mark: I've always (Therapist: mm-hm) thought there was nothing I could do, (Therapist: right) but now I suddenly realize that, all I had to do was not say things like 'oh it's for the best,' you know, or 'the child we have will be better off.' All of the things that that I thought - I guess made me feel better about the decision (Therapist: mm-hm) made you feel, like you, couldn't even talk to me about it so, so although I thought it was, maybe worked for me (Therapist: mm$\mathrm{hm}$ ) I never really thought 'oh what works for you' I mean I guess I never really, I don't know I guess I'm just shocked at how I (Therapist: mm-hm) completely - missed the boat on that [Sarah laughs]. 
Sarah: $\quad$ And I feel badly, like, I could see that you really feel badly that I, you know (three-second pause)

Mark: Well, yeah, because it's such a small, such a small thing, I mean, I can't take away all of the (Therapist: mm-hm) the, the, the pain and the sadness (Therapist: mm-hm) but, if all I had to do was (two-second pause) validate her, feelings, then it - (Therapist: mm-hm) seems, I don't want to use the word selfish, but, it wasn't something done selfishly, it was just, ignorance, I guess. (Therapist: mm-hm) I just didn’t

Therapist: And I guess you're sort of also, in saying that, 'I can understand why you - feel like I, was selfish at times, or.'

Mark: $\quad$ Sure. (Therapist: mm-hm) - well, yeah, I mean, she’s used the word selfcentered, so, (Therapist: mm-hm) I can understand why you would think that I was, self-centered around the whole thing because I (three-second pause) (Therapist: mm) (two-second pause) but I, to be honest I, it's never, you know in all the time that we've been coming and we've talked about this, none of it's ever really made any sense to me (Therapist: mm-hm) and now for the very time it's all (four-second pause)

Sarah: Well, what happened today that made it make sense? (Therapist: mm-hm) what did I say differently? (Three-second pause) Or maybe I didn’t say anything differently?

Mark: Just the way that, you explained that it how it made you feel sad, and you carried the sadness with you every day and it, it affected, you know it was, it was this thing that you, regret, feel powerless all of those things, and it wasn't about - how, I forced you to, like, the - my usual way of dealing with it is, you know, I forced you into the making the decision, it was an immoral one, you've had a hard time with it, um, but mostly because, you're angry at me for making the decision. Those things are totally different from - feeling sad; being angry and being sad are two things that, to me, are separate. (Therapist: mm-hm) So I didn't see you as, sad or, it was angry about it. (Therapist: mm-hm) So now I see you as sad about it, and the anger is just, the ab- If you had been able, if we had been able to talk about it, and I hadn't, um (two-second pause) negated your your - your, feelings about it, (Sarah: then it wouldn't) then it wouldn't have transferred into anger and (Sarah sighs) So I see my role in it as different than just being (Therapist: the recipient of the anger) the decision. (Therapist: mm$\mathrm{hm})(. .$.$) To me it's always been the decision that was sort of the, the biggest$ thing that I did to make it impossible for you to get over it, where as now it's, it's (...) how (two-second pause) I guess unsympathetic I was, so, and not that I didn’t (Therapist: mm, so what) not that I didn't feel sympathy, but just, my inability to express, sympathy in a way that was, helpful to you at all.

The above turns indicate the depth of Mark's newfound understanding and his ability to apply this. Mark's clarification of the role of being able to see Sarah's hurt and pain as instrumental in leading to this (i.e., her hurt becoming experientially available to him leading to 
A Case Study Investigating Whether the Process of Resolving Interpersonal Problems in

his being able to open towards and see things from her perspective) is also consistent with RoPES 3.7 (softening).

\section{Sarah's Response to Developing a Shared Understanding (Meaning Bridge) With Mark (Ropes} 4).

Therapist: Mm-hm, well, what, what happens when you hear him?

Sarah: $\quad$ Well, I feel, a sense of relief.

Therapist: Mm-hm, can you tell him, like, what you're relieved ab-, I'm relieved, or, feel?

Sarah: Well, just, that - (sighs) so, now I can talk to you, and that you won't say those things again. (Therapist: mm-hm) I mean, I can hear the, logical reasons as to why, it [the abortion] was a good thing (Therapist: mm-hm) - which, like you said, never, really, helped, me - it would help you, but it didn't help me. (Therapist: mm-hm) So that now, if I want to discuss it with you, and not necessarily, not necessarily [to] say that I'm going to want to discuss it with you, (Mark: mm-hm) but so you know that if I do, that hopefully you will remember that (Mark: mm-hm) and we can just discuss it from the standpoint of, just feeling sad today because (Therapist: $\mathrm{mm}$ ) whatever.

In this passage, Sarah let Mark know how much it meant to her to have him include her positions in his meaning- and decision-making; these comments also suggest that having her positions included by Mark was leading to feelings of the problem between them becoming resolved. Sarah also indicated how she'd like to see him apply (RoPES 5) his new understanding. With the therapist's encouragement, she continued in this vein.

Therapist: What else, comes up? What's happening in just, the focus on your body?

Sarah: $\quad$ (Three-second pause) Well - like a load has been (Therapist: mm-hm) maybe shared, you know, not just carried by me.

Therapist: Mm-hm, (two-second pause) feels, can you tell him like you're sharing, the load?

Sarah: $\quad$ You can't begin to understand the sadness and the guilt, or maybe you don't think it's appropriate or, I guess not. Now the issue, the issue is that it exists and you know, it's (Therapist: mm-hm) so it's well it's helpful if you, you know, that he could be there for me. That would be good.

Therapist: Yeah, can you tell him, 'I need you to be there for me'?

Sarah: $\quad$ Yeah

Therapist: Look at him

Sarah: (Crying) So I don’t I feel so alone. 
A Case Study Investigating Whether the Process of Resolving Interpersonal Problems in

Mark: (Sighs) I’m sorry I haven’t been, all this time.

Sarah: $\quad$ (Three-second pause) I’m sorry too. (Slight laugh.)

Exploring how Mark might apply this understanding to help her not feel alone, the therapist asked Sarah how she would know that he was acknowledging her pain.

Sarah: Well, like maybe holding my hand or something right? (Therapist: mm-hm) so that I would know that he knows (crying).

Therapist: Mm-hm. It's really important for you to feel, for you to feel like he knows how hard it's been for you (Sarah: yup) and how you have been carrying this.

Sarah: $\quad$ Mm-hm (crying) and not to devalue it now that he understands it, (Therapist: yeah) you know? (Therapist: mm-hm, yeah) (Crying) That it’s legitimate.

Therapist: Yeah, but say that to him then.

Sarah: Well, you know - you know, now that you know or understand better that perhaps we could you know, use this to go forward and not feel so alone in this issue, when instances arise when it comes up that you know, I can count on you being there in this new way not in the old way (three-second pause) (inhales) It may never come up again, or it may, I don't know. I can't think of it never coming up again (Therapist: mm-hm) but (crying) I'm feeling closer about it because I think in the past, I know the reason why we have avoided it is because it's always been this thing that's pulled us apart as opposed to you know, bring us together. (Therapist: right) So hopefully we can turn in around so that even though it was a negative experience it can still have a positive effect on the relationship.

Therapist: Sort of like, as good as the relationship has been, this is something you feel has been between you?

Sarah: It's always been there, yeah.

Therapist: And it seems like, right now, 'I'm feeling closer to you.'

Sarah: $\quad$ Mm-hm. (heavy breathing)

Sarah's statements in these turns continued to reinforce how important it was to her to feel like her perspective was meaningful and influential to Mark, and that Mark's increased inclusion of her perspective had led her to feel an increased sense of interpersonal closeness.

\section{Session 7: Applying New Shared Understandings to the Everyday (Ropes 5)}

Predictably, the process of applying (RoPES 5) these new shared understandings to everyday situations did not unfold seamlessly. At first, aspects of their interactions would go 
wrong, re-triggering their problematic cycle. Sarah was the first to recognize that this process was difficult for her.

Sarah: $\quad$ I'm adjusting to the invalidating feeling that Mark may not - in- intentionally make me feel, by- by the way sometimes he reacts to things I say with words or body language that I, that; That's one of my (Therapist: mm-hm) triggers for getting angry, (Therapist: right, okay) and that's something I'm working on.

Mark also admitted struggling to keep their new understandings in mind when Sarah would get triggered.

Mark: [Sarah's] hurt and the sadness just flow so quickly into the anger that I don't even see it happening, like, I'm not even conscious of it, (Therapist: right) it just happens like that - automatically.

And when this happened, he also got triggered.

Mark: It's a two way street, but you know, this idea that it's not her, it's all me, (Therapist: mm-hm) of course I get defensive! And- and this is usually the point where, you know, the conversation's over, because you know, where do you go from here [seemingly referring to the problematic cycle].

When the couple's problematic cycle did unfold, however, they now talked about it. In addition, Mark began to explicitly talk about his own feelings, as well as how their interactions affected him - something both of them had to get used to.

Mark: (Laughs) It's my turn to explain how I feel, you know?

Sarah: Huh?

Mark: $\quad$ It's my turn to explain how I feel about what you're saying.

Mark's laugh seemed to suggest that this new way of interacting was still somewhat odd for him; Sarah's reaction suggested she, too, was still getting used to Mark's new way of being. In addition, the couple reported that Mark's attempts to share his feelings were sometimes experienced by Sarah (sometimes fairly, sometimes not) as rejections of her perspective.

\section{$\underline{\text { Session 10: Early Signs of Resolution (RoPES 6) }}$}

The couple's continued efforts showed signs of paying off by session 10, however.

Mark: I Iwas] able to get beyond the defensiveness (Therapist: mm-hm) because I didn't feel defensive, I felt sympathetic, and, and (Therapist: right) we were trying to work through it. So, for the first time, even though you [Sarah] were very angry, (Therapist: mm-hm) I was able to - step outside of my defensive 
A Case Study Investigating Whether the Process of Resolving Interpersonal Problems in

self. And, and we were able to (Sarah: but) talk, (Sarah: I, I) and, and I felt that it was extremely good for both of us.

Sarah: $\quad$ I, also, was able to step outside my angry self, (Mark: exactly, you were) (Therapist: yeah) even though I was still angry when I was talking to you, but I (Mark: that, no, of course, like) I don't think you got the impression that I was angry at you, (Mark: yeah) like.

Mark: Well, ten minutes later we were talking - calm, cool and collected - and you were sharing how you felt.

\section{Session 11: Termination With Resolution (RoPES 6)}

At termination, both partners' reports were consistent with RoPES 6 (resolution / routinely consulted): although effort was still evident, exploration of the problematic experience of the abortion decision had led to a shared understanding that had become a resource. Both partners spoke of this with a sense of accomplishment and pride.

Sarah: $\quad$ Because I'm conscious of the difference between anger and hurt and (Therapist: mm-hm) you know, and how it can switch in me - (Therapist: right) become the other, at least to the outside world, right? I try to tell people now that I'm hurt (Therapist: $\mathrm{mm}-\mathrm{hm}$ ) before it comes out as anger (...) I'm finding that it's working better not only with Mark, but with all relationships.

Mark also indicated that things were different.

Mark: $\quad$ Now we seem to be at a point where we can immediately start discussing what the problem is and how it, I mean - I think that's one of the (Therapist: yeah) biggest things we've accomplished, is (Sarah: yeah) you can be angry and I don't, sort of, stifle my reaction (Sarah: uh-huh) thinking it's going to escalate into this huge fight. I can diffuse it by saying 'Well, you know, that's that's not fair' or whatever and you're much (three-second pause) I mean it's funny, the whole issue of - um, the, like, that her emotions are bad or feelings are invalid is tied hand-in-hand with the fact that my reactions are also valid, right?

In other words, the couple's mutual understanding had been applied, and had served as a resource that led to new strengths: Each partner had become more inclusive of one another's positions - and their own.

Mark appeared to increasingly include references to his emotions in his conversations with Sarah. For example, Mark shared that

I've always cared what you think about (sigh) me. So when you are critical it really hurts. 
A Case Study Investigating Whether the Process of Resolving Interpersonal Problems in

For her part, Sarah acknowledged that

Sometimes I'm not very good at communicating my concerns. I think they come across (two-second pause) (sigh) if I don't get them out they eat away in me inside (...) so I get them out and they come across - I think they mostly come across as criticisms.

Mark also noted that

I think the whole process (...) of being defensive was to avoid further conflict (...) but the ultimate irony in this whole thing seems to be that - if I'm not defensive and I actually [state my positions], it actually (Therapist: mm-hm) produces a dialogue that that works to resolve it. So (...) I don't think I'll be going back to the defensive (Therapist: right) part anytime soon (...) It seems like the benefits of not being defensive are, have become immediately apparent (Therapist: right) and (Therapist: mm-hm) has worked wonders in terms of helping us resolve conflict.

Sarah also shared an ongoing need.

I need to feel, I need to see, I need to see an emotional response at times (...) that indicates that you're moved by, or motivated by, or you care! It, to me, it symbolizes [that] you care (...) that I'm not experiencing whatever this is all by myself.

Turning to the therapist, Mark shared that "I think the whole experience has been quite good for such huge, um, you know, steps in our - in our lives" - a statement that reflected a clear sense of the couple as an us, a "we." This "we-ness" also appeared to enable both partners to feel safe differentiating their own unique positions.

Mark: Well, like, like Sarah said, you know, um, we don’t have to have a logical (Therapist: right) um, you know, solution to everything - sometimes we'll just choose to (Therapist: right) disagree.

Therapist: Yeah, so that's more of your comfort with disagreeing. Doesn't mean the relationship's going to end, right?

Mark: Right, yeah. (laughs)

\section{Discussion of Observations from Sarah and Mark's Case}

Through the dialogues facilitated in therapy, Sarah and Mark came to increasingly recognize previously unacknowledged aspects of their own and each others' experiences and actions related to the abortion decision; the couple then applied these insights to make changes in how each partner related to themselves and one another, changes that resulted in the resolution of the problematic experience. 
A Case Study Investigating Whether the Process of Resolving Interpersonal Problems in

Couple Therapy Is Isomorphic to the Process of Resolving Problems in Individual Therapy

H.J. Schielke, W.B. Stiles, R.E. Cuellar, J.L. Fishman, C. Hoener, D. Del Castillo,

A.K. Dye, N. Zerubavel, D.P. Walker, L.S. Greenberg

Pragmatic Case Studies in Psychotherapy, http://pcsp.libraries.rutgers.edu

Volume 7, Module 4, Article 4, pp. 477-528, 12-12-11 [copyright by authors]

This process led to changes in each partner's sense of self-in-relationship with their significant other. Sarah became aware that she had not been sharing her underlying concerns and emotional hurt with Mark, and that this had been contributing to problems in their relationship; and Mark became aware of how focusing on what he deemed to be logical devalued Sarah's emotional experiences and led Sarah to feel ignored and uncared-for, resulting in significant problems in (and threatening the stability of) their relationship.

This process also led to changes in each partner's sense of self. Sarah came to increasingly see the value in sharing the more vulnerable aspects of her experience with others, and to recognize the importance of articulating positions related to these experiences that she might previously have left unspoken (i.e., that she may have intrapersonally excluded from interpersonal dialogue). As a result, at the end of therapy, Sarah reported that these parts of herself had become more influential in her meaning- and decision-making, and were now explicitly represented in her interactions with others ("I try to tell people now that I'm hurt...before it comes out as anger... I'm finding that it's working better not only with Mark, but with all relationships”). Similarly, Mark came to realize that his own emotions were also valuable ("I mean it's funny, the whole issue of - um, the, like, that her emotions are bad or feelings are invalid is tied hand-in-hand with the fact that my reactions are also valid, right?”). (Although not the focus of this paper, Mark's increased inclusion of emotion-informed positions at both the inter- and intrapersonal levels is consistent with long-standing hypotheses from psychodynamic and psychodynamically-informed theorists about the relationship between selfand other- relating patterns.)

In addition, this process also led to changes in each partner's sense of (and representations of) the other. Mark came to realize that Sarah was deeply hurt—something he'd previously not been able to see (Mark: "I just didn't - see the sadness of it because that wasn't what was.” Therapist: “being presented to you necessarily?” Mark: “Yeah, yes.”). Once Sarah did explicitly share her hurt, Mark responded to her in a way that demonstrated his caring and concern for her well-being; as a result, Sarah recognized that Mark cared deeply about her pain, and no longer saw him as uncaring and unfeeling (Sarah: "he understands”).

In summary, the partners' progressive inclusion of their significant other's positions resulted in a shift in each partner's sense of the other and their relationship. These shifts coincided with an increased sense of interpersonal closeness (Therapist: "I'm feeling closer to you” Sarah: "Hm-hm”) and we-ness (Mark: “we don’t have to have a logical... solution to everything”), a we-ness that appeared strong enough to allow for disagreement between voices ("Sometimes we'll just choose to...disagree"). Similarly, the progressive inclusion of intrapersonally-excluded positions (i.e., positions that were not valued or accepted, and were therefore "not me" or "other") coincided with changes in the boundaries of what each considered to be part of their accepted sense of self (i.e., became included in their community of voices).

Throughout this process, dialogue between voices whose positions were in conflict led to therapeutic change. On the way to resolving the problems associated with the way the abortion decision was made, the qualities and outcomes of the patterns of interaction the partners had with one another and "other" parts of themselves progressed in observable ways that were consistent 
A Case Study Investigating Whether the Process of Resolving Interpersonal Problems in

with the descriptions recorded in the RoPES. Given the structural isomorphism between the APES and the RoPES, these observations offered support for the hypothesis that the resolution of problematic experiences between partners in couple therapy evidences a structure and sequence of relational configurations consistent with those identified in prior research on intra-individual therapeutic progress.

\section{GENERAL DISCUSSION}

The theory-building case study presented here facilitated the further elaboration of a model of therapeutic change that was originally developed and repeatedly refined in response to the close study of individual therapy cases. The ongoing elaboration of this model has led researchers to shift from a predominantly cognitive framework that uses the lens of assimilation and accommodation (Stiles et al., 1990) towards an increasingly dialogical model (e.g., Stiles, 1997; Honos-Webb \& Stiles, 1998; Brinegar et al., 2006; Osatuke \& Stiles, 2006; Stiles et al., 2006) that attends to changes in relationships between intrapersonal voices. The case presented here contributed to explicitly extending the model's applicability to the interpersonal realm by assessing and refining the model's ability to describe therapeutic change in couple therapy.

We had interpreted the systems theory principle of isomorphism as suggesting that formal similarities should be evident in the patterns of intra- and interpersonal dialogues observed on the way to therapeutic change, providing encouragement that both levels might be able to be described in a single language system; furthermore, findings from research on close relationships and the model's use of interpersonally-derived language to describe intrapersonal process offered additional encouragement that this might be possible. Consistent with this systems-theoryinformed isomorphism hypothesis, the patterns of interpersonal relationship we observed on the way to therapeutic change in Sarah and Mark's couple therapy evolved in a sequence that was isomorphic to the APES' descriptions of therapeutic change between intrapersonal voices. Comparing material from Sarah and Mark’s therapy that ran contrary to, was un- (or under-) described by, or offered confirmation of the evolving theory led to iterative refinements of the model, refinements that were then submitted for feedback until all judges deemed that the model fit the case observations.

Developing such a model involved selecting language that fit the inter- and intrapersonal levels. We refer to the resulting sequence as the resolution of problematic experiences sequence (or RoPES). This sequence describes a series of relationships observed during the process of developing (and building upon) understanding between voices. The primary focus in the present paper was on demonstrating the RoPES' ability to describe interpersonal therapeutic change.

Based on our case observations, however, the model appears applicable to the intrapersonal level as well (e.g., Schielke et al., 2009, Schielke, 2010). (See the sections entitled "Mark's increasing intrapersonal recognition" and "Sarah clarifies her experience of the problem" for explicitalbeit limited - examples of the model's application to intrapersonal change in the present paper.) 
A Case Study Investigating Whether the Process of Resolving Interpersonal Problems in

The observations informing the RoPES suggest that events representing the effective exclusion of relevant voices' positions (e.g., Sarah's feeling like she did not have any choice but to agree to an abortion) are associated with reports of significant psychological pain. Conversely, the inclusion of once-excluded positions is associated with reports of therapeutic gains. These observations suggest that voices want to be heard when their positions are relevant to an active meaning- or decision-making process. Put in the language of the theory, we might say that voices want their positions to be included (i.e., valued and influential) in relevant meaning-and decision-making processes. This account provides a theoretical explanation for problematic experiences and their resolution. Events are experienced as problematic when relevant voices' positions are excluded from influence; and problems are resolved as relevant voices' positions are included in meaning- and decision-making.

These observations also suggest that it is dialogue between voices that enables positions that were previously excluded (or were seemingly unheard) to come to be empathically understood and included (i.e., valued and influential) in meaning- and decision-making. These changes correspond with a shift from an essentially competitive relationship between voices, where each voice's positions might be described as gaining or losing influence, to a collaborative one, where each voice's positions are influential. In the resulting collaborative relationship, voices actively include one another's positions in meaning- and decision-making.

In respect to the structure of the RoPES, case observations supported the addition (and led to the refinement) of descriptions of both voices' perspectives throughout the developmental process (e.g., RoPES 4 is titled insight / empathically understood). Observations also led to the identification of a new sub-stage in the clarification stage (stage 3) of the RoPES; this in turn led to a re-numbering of the RoPES 3 sub-stages. The name of the new sub-stage (softening / opened towards, sub-stage 3.7) was inspired by emotion-focused therapy's terminology for similar observations (e.g., Elliot, Watson, Goldman, \& Greenberg, 2004; Greenberg \& Goldman, 2008; Greenberg \& Johnson, 1988). EFT uses the term softening to refer to a change event marked by an opening towards the perspective (subjective experience) of the other in response to the other making their hurt, vulnerability, or attachment-related concern explicit. Put in the language of the dialogical model presented here, in successful therapies, when the hurt associated with another voice's experience of the problem becomes experientially available, the voice of focus opens towards the other voice's positions.

\section{Resonances With Other Literature}

The dialogical model of therapeutic change that emerged out of this work is consistent with calls for a framework that offers a means of tracking dyadic interaction (e.g., Guerin \& Chabot, 1992). The model's emphasis on inclusion in dialogue and its description of therapeutic change being associated with a shift from competitive to collaborative relationships is also found in Fishbane’s (1998) Buber-informed (e.g., 1958, 1965) dialogical approach to couple therapy.

As a model that offers a dialogically-focused narrative description (Osatuke et al., 2004) or meta-story about the process of therapeutic change, the model presented here is linked to work on the dialogical / multivoiced self and the literature on narrative psychology. The model's 
focus on inclusion and exclusion as lenses for attending to therapeutic change is also consistent with others' work in the dialogical and narrative fields. Literature on the evolution of narratives about the self and meaning-making in therapy repeatedly refers to the therapeutic importance of developing narratives that more comprehensively represent (i.e., include) all aspects of a person’s experience (e.g., Angus \& McLeod, 2004; Baerger \& McAdams, 1999; McAdams, 1997; McAdams, 2001; McLeod, 1997). In regards to the dialogical / multivoiced self literature, while discussing a series of articles on "Multiplicity of the Self in Psychotherapy" in a special issue of the Journal of Clinical Psychology (Volume 63, Issue 2, 2007), Power notes that

All of the therapies [discussed in this special issue] agree on the importance of a formulation and intervention that identifies which aspects of the self are overly dominant and which aspects have been excluded or ignored; that therapy has to be about opening up the individual to being more flexible and less rigid; and that the experience of a variety of emotions provides one of the key ways of broadening the self-concept to be more inclusive of excluded states [italics added] (Power, 2007, pg. 196).

Research on the social psychology construct of interpersonal exclusion can be interpreted as offering support for the theory's descriptions at the interpersonal level. For example, like the theory presented here, social psychology research suggests that interpersonal exclusion results in psychological pain (triggering the same areas of the brain as physical pain; Eisenberger et al., 2003; Eisenberger \& Lieberman, 2005). Being excluded is associated with anxiety (Baumeister \& Tice, 1990), loneliness, depression, and low self-esteem (Leary, 1990). Self-esteem decreases as experienced exclusion increases (Leary et al., 1995). Exclusion negatively impacts selfregulation (Baumeister et al., 2005) and cognitive functioning (Baumeister et al., 2002), and can lead to a state in which self-awareness, meaningful thought, and long-term thinking are reduced (Twenge et al., 2003). Being ignored is experienced as more distressing and more disruptive to a sense of meaningful existence and feelings of belonging, self-esteem, and control than being involved in an argument; while being included increases ratings on these same variables (Zadro et al., 2005). Each of these findings is consistent with the implications of the presented model as reflected in the RoPES.

\section{Clinical Implications}

The model of change presented here proposes that the exclusion (or anticipated exclusion) of valued positions lies at the root of problematic experiences, and that problems are resolved as voices' positions are included (valued and influential) in relevant meaning- and decision-making. If correct, this suggests that therapists should be curious about which salient positions might be excluded, and facilitate their progressive inclusion in how clients regard and engage themselves and others. Different theoretical orientations offer differing means of facilitating this process (e.g., exposure therapy; tracking worksheets; empathic exploration; multi-chair dialogues; free association; dreamwork; or journaling). Each of these methods has the effect of facilitating dialogue between (and about) divergent positions that increases the likelihood that excluded positions can become more experientially influential. In the cases observed, this was largely facilitated through encouraging clients' curiosity about and empathy with these positions. 
A Case Study Investigating Whether the Process of Resolving Interpersonal Problems in

Couple Therapy Is Isomorphic to the Process of Resolving Problems in Individual Therapy

H.J. Schielke, W.B. Stiles, R.E. Cuellar, J.L. Fishman, C. Hoener, D. Del Castillo,

A.K. Dye, N. Zerubavel, D.P. Walker, L.S. Greenberg

Pragmatic Case Studies in Psychotherapy, http://pcsp.libraries.rutgers.edu

Volume 7, Module 4, Article 4, pp. 477-528, 12-12-11 [copyright by authors]

The RoPES offers descriptions of a sequence of dialogical relationships observed during the process of resolving problematic experiences. If these are accurate, comparing clients' narratives to these patterns may help therapists make sense of clients' therapeutic tasks relative to the problematic experience in question and be able to predict the trajectory of clients' therapeutic process. This, in turn, might help therapists be appropriately responsive (Stiles, Honos-Webb, \& Surko, 1998).

Finally, the observations that informed this model suggest a means of understanding and working with therapeutic impasses. Case observations (see, e.g., "Sarah's revelations and a return to rapid cross-fire,” above) led to the theoretical suggestion that being stuck in a pattern implies that the positions of at least one voice are not being heard (i.e., are not experienced as influencing meaning- and decision-making). If the model is correct in asserting that therapeutic change unfolds through the inclusion of excluded positions, then this suggests that the impasse will persist as long as these positions remain unheard. Clients that fit this description might be invited to engage in interventions aimed at encouraging the recognition, expression, and acceptance of under-included positions.

\section{Limitations and Suggestions for Future Research}

This model represents a first attempt at elaborating a theory that can describe and explain intra- and interpersonal process in the resolution of problematic experiences; it should be treated as such. Although the statements elaborated through this effort rest upon the work to date on the assimilation model, and were intersubjectively found to successfully describe the resolution process in the successful cases studied, these statements rest on observations from two successful couple therapy cases (Schielke, 2010). Generalizability is further potentially limited by the many characteristics (e.g., cultural, socio-economic) that these cases had in common. The elaborations of RoPES stages 0 and 1, while based on case observations, were largely based on clients' retrospective descriptions, and are therefore possibly impacted by recall distortions.

To increase confidence in the statements elaborated through this effort, observations from a diverse range of cases, and by more (and, preferably, different) researchers are required. Future work examining and extending the model's ability to describe intra- and interpersonal process should treat the statements of the model as tentative descriptions open to refinement. Further study of the model's applicability in relation to couple therapies is recommended. Studying the model in relation to family therapies of more than two persons is also recommended. Finally, since applying the principle of isomorphism to therapeutic change at intra- and interpersonal levels suggests that insights about intrapersonal dialogues and relationships (which are not always observable) may be gained by attending to patterns in interpersonal dialogues and relationships (which are far more open to observation), an obvious next step would be to assess the RoPES' ability to describe individual therapies, thereby bringing the assessment of isomorphism in intra- and interpersonal therapeutic change full circle.

As a model elaborated to be experientially resonant with collaborators from varying theoretical backgrounds, it is hoped that this model and the patterns described in the RoPES 
A Case Study Investigating Whether the Process of Resolving Interpersonal Problems in

resonate with personal experience-and that the model continues to be refined to better capture that experience.

\section{REFERENCES}

Angus, L. E., \& McLeod, J. (2004). The handbook of narrative and psychotherapy: Practice, theory, and research. Thousand Oaks, CA: Sage Publications.

Baerger, D. R., \& McAdams, D. P. (1999). Life story coherence and its relation to psychological well-being. Narrative Inquiry, 9, 69-96

Baumeister, R.F., Twenge, J.M., \& Nuss, C. (2002). Effects of social exclusion on cognitive processes: Anticipated aloneness reduces intelligent thought. Journal of Personality and Social Psychology, 83, 817-827.

Baumeister, R.F., Dewall, C.N., Ciarocco, N.J., \& Twenge, J.M. (2005). Social exclusion impairs self-regulation. Journal of Personality and Social Psychology, 88, 589-604.

Baumeister, R. F., \& Tice, D. M. (1990). Anxiety and social exclusion. Journal of Social and Clinical Psychology, 9, 165-195.

Benjamin, L. S. (2006). Interpersonal reconstructive therapy: An integrative, personality-based treatment for complex cases. New York, Guilford.

von Bertalanffy, L. (1968). General System theory: Foundations, development, applications. New York, George Braziller.

Breunlin, D.C., Schwartz, R.C. \& Mac Kune-Karrer, B. (1992). Metaframeworks: Transcending the Models of Family Therapy. San Francisco: Jossey-Bass.

Brinegar, M. G., Salvi, L. M., Stiles, W. B., \& Greenberg, L. S. (2006). Building a meaning bridge: Therapeutic progress from problem formulation to understanding. Journal of Counseling Psychology, 53, 165-180.

Brinegar, M. G., Salvi, L. M., \& Stiles, W. B. (2008). The case of Lisa and the assimilation model: The interrelatedness of problematic voices, Psychotherapy Research, 18, 657666.

Bromberg, P. M. (1998). Standing in the spaces. Hillsdale, NJ: Analytic Press.

Buber, M. (1958). I-thou. New York: Charles Scribner's Sons.

Buber, M. (1965). The knowledge of man: Selected essays. New York, NY: Harper \& Row Publishers.

Carrere, S., \& Gottman, J.M., (1999). Predicting Divorce among Newlyweds from the First Three Minutes of a Marital Conflict Discussion, Family Process, 38, 293-301.

Catherall, D. R. (2007). Emotional Safety: Viewing couples through the lens of affect. New York, Routledge.

Detert, N., Llewelyn, S., Hardy, G. E., Stiles, W. B., \& Barkham, M. (2006). Assimilation in good and poor outcome cases of very brief psychotherapy for mild depression. Psychotherapy Research, 16, 393-407.

Eisenberger, N. I., Lieberman, M. D., \& Williams, K. D. (2003, October 10). Does rejection hurt? An fMRI study of social exclusion. Science, 302, 290-292.

Eisenberger, N. I., \& Lieberman, M. D. (2005). Why it hurts to be left out: The neurocognitive overlap between physical and social pain. In K. D. Williams, J. P. Forgas, \& W. von 
A Case Study Investigating Whether the Process of Resolving Interpersonal Problems in

Couple Therapy Is Isomorphic to the Process of Resolving Problems in Individual Therapy

H.J. Schielke, W.B. Stiles, R.E. Cuellar, J.L. Fishman, C. Hoener, D. Del Castillo,

A.K. Dye, N. Zerubavel, D.P. Walker, L.S. Greenberg

Pragmatic Case Studies in Psychotherapy, http://pcsp.libraries.rutgers.edu

Volume 7, Module 4, Article 4, pp. 477-528, 12-12-11 [copyright by authors]

Hippel (Eds.), The social outcast: Ostracism, social exclusion, rejection, and bullying (pp. 109-130). New York: Psychology Press.

Elliott, R. \& Greenberg, L. (1997). Multiple voices in process-experiential therapy: Dialogues between aspects of the self. Journal of Psychotherapy Integration, 7, 225-239.

Elliott, R., Watson, J., Goldman, R. N., \& Greenberg, L. S. (2004). Learning Emotion-Focused Therapy: The process-experiential approach to change. Washington, DC, American Psychological Association Press.

Enright, R.D., Rique, J., \& Coyle, C.T. (2000). The Enright Forgiveness Inventory (EFI) user's manual. Madison: The International Forgiveness Institute.

Fishbane, M. D. (1998). I, thou and we: A dialogical approach to couples therapy. Journal of Marriage and Family Therapy, 24, 41-58.

Gottman, J. M. (1994). What predicts divorce? Hillsdale, NJ: Lawrence Erlbaum Assoc.

Gottman, J. M., (1999). The marriage clinic. New York: Norton.

Gottman, J. M., Coan, J., Carrere, S., \& Swanson, C., (1998). Predicting marital happiness and stability from newlywed interactions, Journal of Marriage and the Family, 60, 5-22

Gottman, J. M., \& Levenson, R.W. (1999). What predicts change in marital interaction over time? A study of alternative models. Family Process, 38, 143-158.

Gottman, J. M, Murray, J., Swanson, C., Tyson, R., \& Swanson, K., (2002). The mathematics of marriage: Dynamic nonlinear models. Cambridge, MA: MIT Press.

Greenberg, J. R., \& Mitchell, S. A. (1983). Object relations in psychoanalytic theory. Cambridge, MA: Harvard University Press

Greenberg, L. S., \& Goldman, R. N. (2008). Emotion-Focused Couples Therapy: The dynamics of emotion, love and power. Washington, DC: American Psychological Association.

Greenberg, L., Warwar, S., \& Malcolm, W. (2010). Emotion-focused couples therapy and the facilitation of forgiveness. Journal of Marriage and Family Therapy, 36, 28-42.

Guerin, P. J., \& Chabot, D. R. (1992). Development of family systems theory. In D. Freedheim (Ed.), History of psychotherapy: A century of change (pp. 225-260). Washington, DC: American Psychological Association.

Hermans, H. J. M., \& Dimaggio, G. (2004). The dialogical self in psychotherapy. Hove, East Sussex: Brunner-Routledge.

Hermans, H. J. M., \& Kempen, H. J. G. (1993). The dialogical self: Meaning as movement. San Diego, CA: Academic Press. Inc.

Hermans, H. J. M. (2004). The innovation of self-narratives: A dialogical approach. In L. E. Angus \& J. McLeod (Eds.), The handbook of narrative and psychotherapy: Practice, theory, and research (pp. 175-191). Thousand Oaks, CA: Sage Publications.

Honos-Webb, L., \& Stiles, W. B. (1998). Reformulation of assimilation analysis in terms of voices. Psychotherapy, 35, 23-33.

Leary, M. R. (1990). Responses to social exclusion: Social anxiety, jealousy, loneliness, depression, and low self-esteem. Journal of Social and Clinical Psychology, 9, 221-229.

Leary, M. R., Tambor, E. S., Terdal, S. K., \& Downs, D. L. (1995). Self-esteem as an interpersonal monitor: The sociometer hyphothesis. Journal of Personality and Social Psychology, 68, 518-530.

Linehan, M. M. (1993). Cognitive-behavioral treatment of borderline personality disorder. New York: Guilford Press. 
A Case Study Investigating Whether the Process of Resolving Interpersonal Problems in

Couple Therapy Is Isomorphic to the Process of Resolving Problems in Individual Therapy

H.J . Schielke, W.B. Stiles, R. E. Cuellar, J.L. Fishman, C. Hoener, D. Del Castillo,

A.K. Dye, N. Zerubavel, D.P. Walker, L.S. Greenberg

Pragmatic Case Studies in Psychotherapy, http://pcsp.libraries.rutgers.edu

Volume 7, Module 4, Article 4, pp. 477-528, 12-12-11 [copyright by authors]

Mair, J. M. M. (1977). The community of self. In D. Bannister (Ed.), New perspectives in personal construct theory (pp. 125-149).

Markman, H. J., \& Hahlweg, K. (1993). The prediction and prevention of marital distress: an international perspective. Clinical Psychology Review, 13, 29-43.

Matthews, L. S., Wickrama, K.A.S. and Conger, R. D., (1996) Predicting marital instability from spouse and observer reports of marital interaction. Journal of Marriage and the Family, 58, 641-655.

McLeod, J. (1997). Narrative and psychotherapy. London: Sage Publications.

McAdams, D. P. (1997). The case for unity in the (post)modern self. In R. D. Ashmore \& L. Jussim (Eds). Self and identity: Fundamental issues (pp. 46-78). New York: Oxford University Press.

McAdams, D. P. (2001). The psychology of life stories. Review of General Psychology, 5, 100122.

Nickerson, R. S. (1998). Confirmation bias: A ubiquitous phenomenon in many guises. Review of General Psychology, 2, 175-220.

Osatuke, K., Glick, M. J., Gray, M. A., Reynolds, D. J., Jr., Humphreys, C. L., Salvi, L. M., \& Stiles, W. B. (2004). Assimilation and narrative: Stories as meaning bridges. In L. Angus \& J. McLeod (Eds.), Handbook of narrative and psychotherapy: Practice, theory, and research (pp. 193-210). Thousand Oaks, CA: Sage.

Osatuke, K., \& Stiles, W. B. (2006). Problematic internal voices in clients with borderline features: An elaboration of the assimilation model. Journal of Constructivist Psychology, 287-319.

Peirce, C. S. (1931-1958). The collected papers of Charles Sanders Peirce (Vol. 1-8; C. Hartshorne, P. Weiss, \& A. Burks, Eds.). Cambridge, MA: Harvard University Press.

Pinsof, W. M. (1995). Integrative problem-centered therapy: A synthesis of biological, individual and family therapies. New York: Basic Books.

Postmes, T., Spears, R., \& Cihangir, S. (2001). Quality of decision making and group norms. Journal of Personality and Social Psychology, 80, 918 - 930.

Power, M. J. (2007). The multistory self: Why the self is more than the sum of its autoparts. Journal of Clinical Psychology, 63, 187-198.

Reid, D. W., Dalton, E. J., Laderoute, K., Doell, F. K., \& Nguyen, T. (2006). Therapeutically induced changes in couple identity: The role of we-ness and interpersonal processing in relationship satisfaction. Genetic, social and general psychological monographs, 132, 241-283.

Ribeiro, A. P., Bento, T., Salgado, J., Stiles, W. B., \& Gonçalves, M. M. (2011). A dynamic look at narrative change in psychotherapy: A case study tracking innovative moments and protonarratives using state-space grids. Psychotherapy Research, 21, 54-69.

Rowan, J. (1990). Subpersonalities: The people inside us. New York: Routledge.

Rowan, J., \& Cooper, M. (1999). The plural self: Multiplicity in everyday life. London: Sage Publications.

Ryle, A., \& Fawkes, L., (2007). Multiplicity of selves and others: Cognitive Analytic Therapy. Journal of Clinical Psychology, 63, 165-174.

Schielke, H. J. (2010). The process of including the other: Patterns of interaction, meaning-and decision-making observed on the way to improved relationships with self and others 
A Case Study Investigating Whether the Process of Resolving Interpersonal Problems in

Couple Therapy Is Isomorphic to the Process of Resolving Problems in Individual Therapy

H.J. Schielke, W.B. Stiles, R.E. Cuellar, J.L. Fishman, C. Hoener, D. Del Castillo,

A.K. Dye, N. Zerubavel, D.P. Walker, L.S. Greenberg

Pragmatic Case Studies in Psychotherapy, http://pcsp.libraries.rutgers.edu

Volume 7, Module 4, Article 4, pp. 477-528, 12-12-11 [copyright by authors]

(Unpublished Masters thesis). Department of Psychology, Miami University, Oxford, Ohio.

Schielke, H. J., Cuellar, R. E., Del Castillo, D. M., Dye, A. K, Fishman, J. L., Hoener, C., Walker, D. P., Zerubavel, N., Stiles, W. B., Greenberg, L. S. (2009, June). Inclusion and exclusion in intra- and interpersonal dialogue: A lens for attending to the process of therapeutic change. In C. Martínez Guzmán (Moderator), Voices in the session: The dialogic perspective in psychotherapy research. Paper presented at the 40th Annual Meeting of the International Society for Psychotherapy Research, Santiago, Chile.

Schulz-Hardt, S., Brodbeck, F. C., Mojzisch, A., Kerschreiter, R., \& Frey, D. (2006). Group decision making in hidden profile situations: Dissent as a facilitator for decision quality. Journal of Personality and Social Psychology, 91, 1080 - 1093.

Schwartz, R. C. (1995). Internal Family Systems Therapy. New York: Guilford Press.

Spanier, G. B. (1976). Measuring Dyadic Adjustment: New Scales for Assessing the Quality of Marriage and Similar Dyads. Journal of Marriage \& Family, 38, 15-28.

Stiles, W. B. (1993). Quality control in qualitative research. Clinical Psychology Review, 13, 593-618.

Stiles, W. B. (1997). Signs and voices: Joining a conversation in progress. British Journal of Medical Psychology, 70, 169-176.

Stiles, W. B. (1999). Signs and voices in psychotherapy. Psychotherapy Research, 9, 1-21.

Stiles, W. B. (2002). Assimilation of problematic experiences. In J. C. Norcross (Ed.), Psychotherapy relationships that work: Therapist contributions and responsiveness to patients (pp. 357-365). New York: Oxford University Press.

Stiles, W. B. (2003). When is a case study scientific research? Psychotherapy Bulletin, 38(1), 611.

Stiles, W. B. (2005). Case studies. In J. C. Norcross, L. E. Beutler, \& R. F. Levant (Eds.), Evidence-based practices in mental health: Debate and dialogue on the fundamental questions (pp. 57-64). Washington, DC: American Psychological Association.

Stiles, W. B. (2006). Assimilation model references. Retrieved from the Web January 12, 2007. http://www.users.muohio.edu/stileswb/assimilation_model.htm

Stiles, W. B. (2007). Theory-building case studies of counselling and psychotherapy. Counselling and Psychotherapy Research, 7, 122-127.

Stiles, W. B. (2009). Logical operations in theory-building case studies. Pragmatic Case Studies in Psychotherapy, 5, 9-22. Retrieved from http://jrul.libraries.rutgers.edu/index.php/pcsp/article/view/973/2384

Stiles, W. B., Elliott, R., Llewelyn, S. P., Firth-Cozens, J. A., Margison, F. R., Shapiro, D. A., \& Hardy, G. (1990). Assimilation of problematic experiences by clients in psychotherapy. Psychotherapy, 27, 411-420.

Stiles, W. B., Honos-Webb, L., \& Surko, M. (1998). Responsiveness in psychotherapy. Clinical Psychology: Science and Practice, 5, 439-458.

Stiles, W. B., Leiman, M., Shapiro, D. A., Hardy, G. E., Barkham, M., Detert, N. B., \& Llewelyn, S. P. (2006). What does the first exchange tell? Dialogical sequence analysis and assimilation in very brief therapy. Psychotherapy Research, 16, 408-421.

Sullivan, H. S. (1953). The interpersonal theory of psychiatry. New York: W.W. Norton \& Company, Inc. 
Twenge, J. M., Catanese, K. R., \& Baumeister, R. F. (2003). Social exclusion and the deconstructed state: Time perception, meaninglessness, lethargy, lack of emotion, and self-awareness. Journal of Personality and Social Psychology, 85, 409-423.

Watkins, J.G., \& Watkins, H.H. (1997). Ego states: Theory and therapy. New York: W.W. Norton \& Company, Inc.

Young, J.E., Klosko, J.S., \& Weishaar, M. (2003). Schema therapy: A practitioner's guide. Guilford Publications: New York.

Zadro, L., Williams, K.D., \& Richardson, R. (2005). Riding the “O” Train: Comparing the Effects of Ostracism and Verbal Dispute on Targets and Sources. Group Processes \& Intergroup Relations, 8, 125-143. 


\section{Table 1. Assimilation of Problematic Experiences Sequence (APES)}

0. Warded off/dissociated. Client seems unaware of the problem; the problematic voice is silent, unheard, or dissociated. Affect may be minimal, reflecting successful avoidance. Alternatively, problem may appear as somatic symptoms, acting out, or state switches.

1. Unwanted thoughts/active avoidance. Client prefers not to think about the experience. Problematic voices that emerge in response to therapist interventions or external circumstances are suppressed or actively avoided. Affect involves unfocused negative feelings; their connection with the content may be unclear.

2. Vague awareness/emergence. Client is aware of a problematic voice or experience, and can express it, but cannot reflect on it. Affect includes intense psychological pain--fear, sadness, anger, disgust--associated with the problematic experience.

3. Problem statement/clarification. Content includes a clear statement of a problem--something that can be worked on. Opposing voices are differentiated and can talk about each other. Affect is negative, but manageable, not panicky.

3.2. Rapid Cross-Fire. The problematic voice addresses dominant community but is abruptly cut-off mid-sentence. Rapid cross-triggering of incongruent voices as they fight for possession of the floor. Voices speak for short periods of time with frequent interruptions.

3.4. Entitlement. Problematic voice speaks for a longer period of time without disruption from the dominant community. The voice asserts itself forcefully, feels entitled; speaks with a demanding attitude. Affective expression tends to be assertive, angry.

3.6 Respect and Attention. Voices become more tolerant of each other. They listen to each other without interrupting and are more respectful of the other's position. They each speak for longer, and more equal amounts of time. The content is less emotionally charged and voices are less confrontational. (Voices begin to work towards on problem solving?)

3.8 Joint Search for Understanding. Voices work collaboratively and struggle to understand the problem more clearly; connections are made as awareness grows; approximations of insight become evident. Voices begin to blend and sound less distinctive. (They each sound less discrepant and become harder to identify.)

4. Understanding/insight. The problematic experience is formulated and understood in some way. Voices reach an understanding with each other (a meaning bridge). Affect may be mixed, with some unpleasant recognition but also some pleasant surprise.

5. Application/working through. The understanding is used to work on a problem. Voices work together to address problems of living. Affective tone is positive, optimistic.

6. Resourcefulness/problem solution. The formerly problematic experience has become a resource, used for solving problems. Voices can be used flexibly. Affect is positive, satisfied.

7. Integration/mastery. Client automatically generalizes solutions; once-problematic voices now serve as resources in new situations. Affect is positive or neutral (i.e., this is no longer something to get excited about). 
A Case Study Investigating Whether the Process of Resolving Interpersonal Problems in

Couple Therapy Is Isomorphic to the Process of Resolving Problems in Individual Therapy

H.J. Schielke, W.B. Stiles, R.E. Cuellar, J.L. Fishman, C. Hoener, D. Del Castillo,

A.K. Dye, N. Zerubavel, D.P. Walker, L.S. Greenberg

Pragmatic Case Studies in Psychotherapy, http://pcsp.libraries.rutgers.edu

Volume 7, Module 4, Article 4, pp. 477-528, 12-12-11 [copyright by authors]

\section{Table 2. Pre-iterative version of the Resolution of Problematic Experiences Sequence}

Key to font style meanings: Number is Pattern \#; Bold speaks to relationship with positions that are problematic from the perspective of the dominant voices in a system; Italic is experience of "other," non-dominant voices; Plain text is description from the dominant voice's perspective; Underlined bold speaks to experience that is shared by the voices in question.

0. Unaware / unheard. Dominant voices seem unaware that a problem exists; would-be problematic voices' positions are completely excluded, and are unheard or dissociated. Affect may be minimal, reflecting successful domination of would-be problematic voices. Alternatively, signs of conflict may manifested in somatic symptoms, acting out, or state switches.

1. Actively avoided, suppressed / ignored. Engaging in dialogue with problematic voices is painful, and is actively avoided or suppressed. Affect involves unfocused negative feelings; their connection with the content may be unclear.

2. Vague awareness / misunderstood. Dominant voices are aware of a problem in relation to a voice or experience, and can express it, but cannot reflect on it. Affect includes intense psychological pain-fear, sadness, anger, disgust--associated with the problematic experience.

3. Problem statement, clarification / emerging sense of inclusion. Content includes a clear description of the active dilemma--something that can be worked on. Opposing voices are differentiated and can talk about each other. Affect is negative, but manageable, not panicky.

3.2. Rapid Cross-Fire. The problematic voice addresses the dominant community but is abruptly cutoff mid-sentence. Rapid cross-triggering of incongruent voices as they fight for possession of the floor. Voices speak for short periods of time with frequent interruptions.

3.4. Entitlement. Problematic voice speaks for a longer period of time without disruption from the dominant community. The voice asserts itself forcefully, feels entitled; speaks with a demanding attitude. Affective expression tends to be assertive, angry.

3.6 Respect and Attention. Voices become more tolerant of each other. They listen to each other without interrupting and are more respectful of the other's position. They each speak for longer, and more equal amounts of time. The content is less emotionally charged and voices are less confrontational. (Voices begin to work towards problem solving?)

3.8 Joint Search for Understanding. Voices work collaboratively and struggle to understand the problem more clearly; connections are made as awareness grows; approximations of insight become evident. Voices begin to blend and sound less distinctive. (They each sound less discrepant and become harder to identify.)

4. Insight / empathy / understanding. The problematic experience is jointly formulated and understood in some way. Voices reach a shared understanding with each other (a meaning bridge). Affect may be mixed, with some unpleasant recognition but also some pleasant surprise.

5. Application/working through. The understanding is used to work on a problem. Voices work together to address problems of living. Affective tone is positive, optimistic.

6. Resourcefulness/problem solution. The formerly problematic experience has become a resource, used for solving problems. Voices can be used flexibly. Affect is positive, satisfied.

7. Integration/mastery. Voices automatically generalize solutions; once-problematic voices are now fully included and serve as resources in new situations. Affect is positive or neutral (i.e., this is no longer something to get excited about).

Note: This process is considered as occurring on a continuum; other intermediate stages are also probable. 
A Case Study Investigating Whether the Process of Resolving Interpersonal Problems in

Couple Therapy Is Isomorphic to the Process of Resolving Problems in Individual Therapy

H.J . Schielke, W.B. Stiles, R. E. Cuellar, J.L. Fishman, C. Hoener, D. Del Castillo,

A.K. Dye, N. Zerubavel, D.P. Walker, L.S. Greenberg

Pragmatic Case Studies in Psychotherapy, http://pcsp.libraries. rutgers.edu

Volume 7, Module 4, Article 4, pp. 477-528, 12-12-11 [copyright by authors]

Table 3. Outcome Measure Data: Couple Studied

\begin{tabular}{llllll}
\hline & Outcome Measure & Pre-Treatment & \multicolumn{2}{c}{ Post-Treatment } \\
\hline Sarah and Mark & & Sarah & Mark & Sarah & Mark \\
\hline & Dyadic Adjustment Scale (DAS) & 113 & 106 & 130 & 121 \\
& Enright Forgiveness Inventory (EFI) & 297 & 358 & 335 & 349 \\
\hline $\begin{array}{l}\text { Other Successful } \\
\text { Couple Case }\end{array}$ & & Injured & Injurer & Injured & \multirow{2}{*}{ Injurer } \\
\hline & Dyadic Adjustment Scale (DAS) & 92 & 94 & 121 & 133 \\
& Enright Forgiveness Inventory (EFI) & 289 & 318 & 351 & 349
\end{tabular}

Note: For each measure, higher scores are better. See Table 4 for Mean and Standard Deviation data. 
A Case Study Investigating Whether the Process of Resolving Interpersonal Problems in

H.J . Schielke, W.B. Stiles, R.E. Cuellar, J.L. Fishman, C. Hoener, D. Del Castillo,

A.K. Dye, N. Zerubavel, D.P. Walker, L.S. Greenberg

Pragmatic Case Studies in Psychotherapy, http://pcsp.libraries.rutgers.edu

Volume 7, Module 4, Article 4, pp. 477-528, 12-12-11 [copyright by authors]

Table 4. Outcome Measure Data: Pre- and Post-Treatment Mean and Standard Deviation Data from Emotional Injury Project (EIP)

\begin{tabular}{lllll}
\hline Outcome Measure & Pre-Treatment & \multicolumn{3}{c}{ Post-Treatment } \\
\hline & $\begin{array}{l}\text { Injured } \\
M(S D)\end{array}$ & $\begin{array}{l}\text { Injurer } \\
M(S D)\end{array}$ & $\begin{array}{l}\text { Injured } \\
M(S D)\end{array}$ & $\begin{array}{l}\text { Injurer } \\
M(S D)\end{array}$ \\
\hline $\begin{array}{l}\text { Dyadic Adjustment Scale } \\
\text { (DAS) }\end{array}$ & $85.7(17.4)$ & $89.6(22.6)$ & $98.1(17.7)$ & $100.5(22.0)$ \\
\hline $\begin{array}{l}\text { Enright Forgiveness } \\
\text { Inventory (EFI) }\end{array}$ & $267.7(33.2)$ & $305.3(39.9)$ & $309.3(37.9)$ & $313.8(36.1)$ \\
\hline
\end{tabular}

Notes: For each measure, higher scores are better. In 4 of the 20 couples, both parties reported a long-standing emotional injury; as a result, 24 partners were categorized as "injured partners" and 16 as "injurers". 
A Case Study Investigating Whether the Process of Resolving Interpersonal Problems in

Couple Therapy Is Isomorphic to the Process of Resolving Problems in Individual Therapy

H.J. Schielke, W.B. Stiles, R.E. Cuellar, J.L. Fishman, C. Hoener, D. Del Castillo,

A.K. Dye, N. Zerubavel, D.P. Walker, L.S. Greenberg

Pragmatic Case Studies in Psychotherapy, http://pcsp.libraries.rutgers.edu

Volume 7, Module 4, Article 4, pp. 477-528, 12-12-11 [copyright by authors]

\section{Table 5. The Resolution of Problematic Experiences Sequence (RoPES)}

Key: Bold describes the state of a voice in relation to another voice's positions / italic describes the relationship from the perspective of the other voice. A description of the pattern's qualities follows in plain text.

0. Unaware / unheard. Awareness of a problem does not seem to exist. Voices whose positions would challenge this view are unheard or dissociated, and do not seem to influence relevant meaning- or decisionmaking processes. Affect may be minimal, reflecting effective exclusion of problematic positions. Conflict may become indicated by somatic symptoms, rapid changes in psychological state, or acting out.

1. Active avoidance, suppression, redefinition / ignored. Encountering the other voice's positions about the experience is overwhelmingly threatening; dialogue about these is avoided or suppressed, and the other voice is seen as the cause of the problem. Interpersonally, this may be reflected in disengagement and/or nonverbal signs of discomfort. The problem may also be "explained away." Affect involves unfocused negative feelings (esp. feelings of anxiety and/or depression); their connection with the content may be unclear.

2. Vague awareness / not understood. The voice of focus begins to recognize the existence of a problem, and can express a partial understanding of this, but cannot make sense of it. Progress through this state typically becomes accompanied by significant psychological pain (intense fear, sadness, anger, and/or disgust) in relation to the problematic experience. Emerging questions tend to embed accusations (e.g., "what is wrong with," "how could," "why would") that blame the other voice and discourage exploration.

3. Clarification / increasing recognition. Voices engage one another in active discussion of their conflicting positions, differentiating and clarifying these such that increasingly refined statements of the problem-something that can be worked on -- become formulated. As this process progresses, affect shifts from highly negative to manageable as stances shift from opposition towards collaboration. After the other's hurt becomes experientially available, active curiosity and reflexivity emerge, making recognition possible.

Observable sub-patterns include:

3.1 Rapid cross-fire / disputed. The other voice begins to assert positions, but is abruptly cut-off. Voices fight for possession of the floor, and speak for short periods of time with frequent interruptions.

3.3 Listening / tolerated, listened-to. The other voice demands to be heard, feels entitled to differentiate and assert positions, and speaks for longer periods of time; tone may be assertive, demanding, or angry.

3.5 Attending / respected. Voices are less defensive, more respectful of each other's positions, and listen to each other without interrupting. Positions are less oppositional, and a broader range of affect is evident.

3.7 Softening / opened towards. The hurt associated with the other voice's experience of the problem becomes experientially available; the voice of focus opens towards the other's positions.

3.9 Exploring / tentatively recognized. Voices jointly struggle to understand the problem more clearly; the voice of focus is actively curious about the other's positions, and reflexivity emerges. Connections are made as awareness grows; approximations of insight become evident. Voices' positions begin to converge.

4. Insight / empathically understood. Voices experience a sense of shared understanding about the problematic experience -- a meaning bridge has been created. Affect is likely to be powerful, and may be mixed; there may be some unpleasant recognition of having contributed to the problem, as well as some pleasant surprise: the problem is experienced as resolvable.

5. Working through / applied. Voices work together to explore and apply implications of hard-won insight towards problem resolution; alternate courses of action may be considered and weighed against one another. Affect grows more consistently positive as tangible progress toward a workable solution is achieved.

6. Resolution / routinely consulted. The once-problematic experience is resolved and has become a resource, and the once-problematic voice is now routinely consulted in relevant decision-making processes. Voices are flexibly included; some effort is still evident in this process, however. Related affect is positive, satisfied, reflecting feelings of pride, accomplishment.

7. Mutual inclusion / mutually included. The once-problematic voice is now fully trusted and automatically included in meaning- and decision-making processes. Voices effortlessly generalize solutions that are mutually supported. Affect is generally positive or neutral (i.e., this is no longer something to get excited about). 


\section{Figure 1: Iterative Abduction Process Overview}

\section{Preparation:}

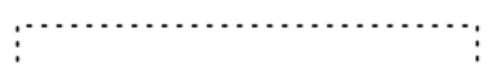

\section{Principal Investigator (PI) prepares model document for iterative refinement}

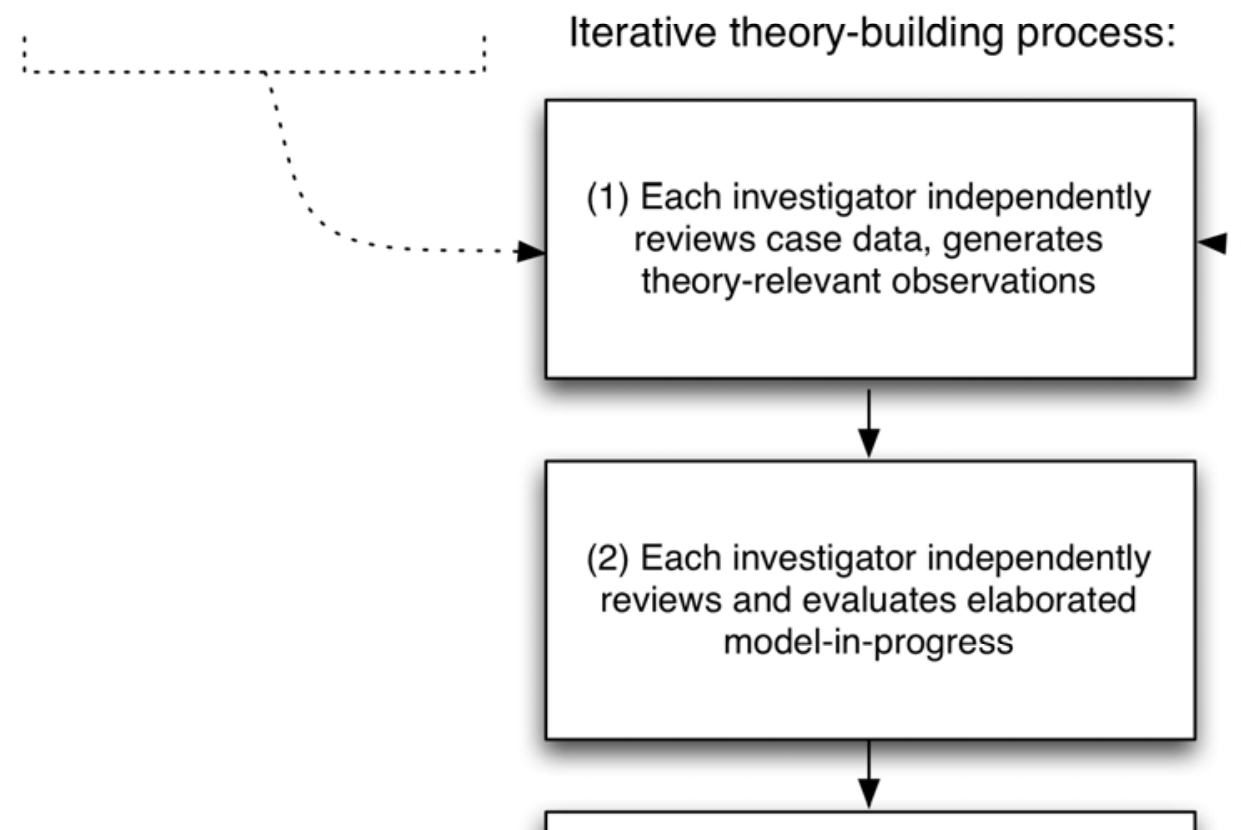

(3) PI reviews investigator observations and model feedback; meets with team to ensure accurate understanding of co-investigator feedback

\section{Submit new iteration of model for feedback}

(4) PI generates next iteration of elaborated model-in-progress, using commenting features to draw coinvestigators' attention to (and clarify rationale for) any changes 